\title{
Decoding rRNA sequences for improved metagenomics in sylvatic mosquito species
}

\author{
Cassandra Koh ${ }^{1}$, Lionel Frangeul ${ }^{1}$, Hervé Blanc ${ }^{1}$, Carine Ngoagouni², Sébastien Boyer ${ }^{3}$, Philippe \\ Dussart ${ }^{4}$, Nina Grau ${ }^{5}$, Romain Girod ${ }^{5}$, Jean-Bernard Duchemin ${ }^{6}$ and Maria-Carla Saleh ${ }^{1 *}$ \\ 1 Viruses and RNA Interference Unit, CNRS-URM3569, Department of Virology, Institut Pasteur, Paris \\ Cedex 15 75724, France \\ ${ }^{2}$ Medical Entomology Laboratory, Institut Pasteur de Bangui, Bangui PO Box 923, Central African \\ Republic \\ ${ }^{3}$ Medical and Veterinary Entomology Unit, Institut Pasteur du Cambodge, Phnom Penh 12201, \\ Cambodia \\ ${ }^{4}$ Virology Unit, Institut Pasteur du Cambodge, Phnom Penh 12201, Cambodia \\ ${ }^{5}$ Medical Entomology Unit, Institut Pasteur de Madagascar, Antananarivo 101, Madagascar \\ ${ }^{6}$ Vectopôle Amazonien Emile Abonnenc, Institut Pasteur de la Guyane, Cayenne 97306, French \\ Guiana
}

* To whom correspondence should be addressed. Tel: +33 1456885 47; Fax: +3314568 87 27; Email: carla.saleh@pasteur.fr

Present address: Philippe Dussart, Institut Pasteur de Madagascar, Antananarivo 101, Madagascar; Nina Grau, Sciences Economiques et Sociales de la Santé et Traitement de l'Information Médicale, Faculté de Médecine, Marseille 13005, France

\section{ABSTRACT}

RNAseq-based metagenomics on mosquitoes are frequently performed for surveillance or microbiome discovery studies to understand the disease ecology of arboviruses. A major hurdle to overcome in these studies is the depletion of abundant rRNA, which is commonly achieved using oligo-based protocols. The lack of complete reference rRNA sequences in sequence databases for most mosquito vectors makes such studies feasible for only a narrow range of species, biasing the knowledge on mosquitoes and their viruses. We performed total RNAseq and mitochondrial cytochrome c oxidase I gene sequencing on specimens of 29 mosquito species to compare the functionality of rRNA sequences as an "RNA barcode" for taxonomy and phylogeny. Using a scorebased strategy to bioinformatically filter out contaminating rRNA reads, we successfully assembled full-length $28 \mathrm{~S}$ and $18 \mathrm{~S}$ rRNA sequences for all specimens. Phylogenetic reconstructions revealed a high degree of congruity between DNA and RNA barcodes. This assembly strategy presented here and the expansion of the rRNA reference library in public databases by 232 new complete $28 S$ and $18 S$ rRNA sequences provide new tools to improve surveillance and microbiome discovery for a more holistic understanding of arbovirus-transmission by mosquitoes in designing preemptive measures. 
bioRxiv preprint doi: https://doi.org/10.1101/2022.02.01.478639; this version posted February 3, 2022. The copyright holder for this preprint (which was not certified by peer review) is the author/funder, who has granted bioRxiv a license to display the preprint in perpetuity. It is made available under aCC-BY-NC 4.0 International license.

\section{GRAPHICAL ABSTRACT}

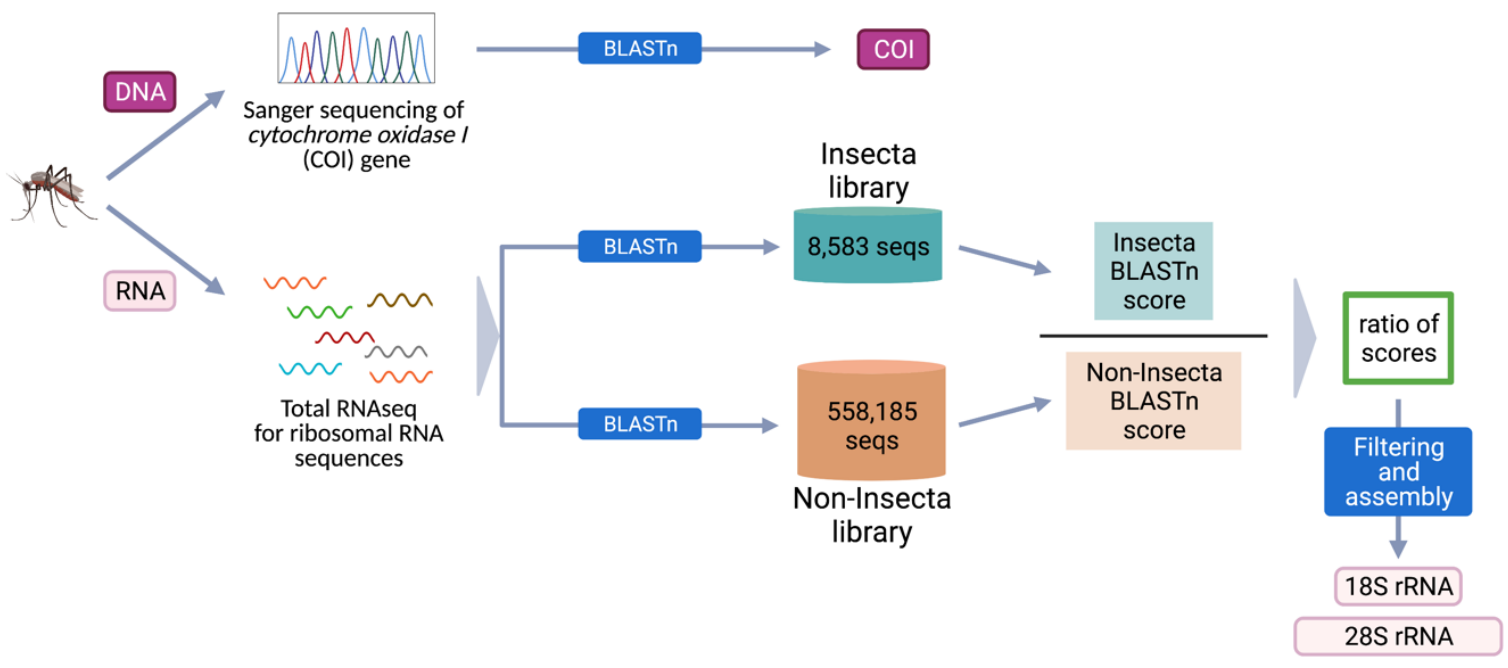




\section{INTRODUCTION}

Mosquitoes top the list of vectors for arthropod-borne diseases and are implicated in the transmission of many human pathogens responsible for arboviral diseases, malaria, and lymphatic filariasis (1). Metagenomic studies on field-captured mosquito specimens for the purposes of surveillance and microbiome or pathogen discovery are becoming increasingly important under the One Health concept, which emphasizes the importance of considering biotic and abiotic elements existing within the same ecosystem to address neglected zoonotic diseases (2). With next-generation sequencing technologies becoming more accessible, these studies are increasing in frequency, giving us an understanding of the interfaces among mosquitoes, their environment, and their animal and human hosts. Currently, there is a strong focus on only a handful species from the three genera of mosquitoes (Aedes, Culex and Anopheles) due to their medical importance and anthropophilic behavior despite evidence that other species are also competent for the pathogens in question. The inclusion of lesser studied but ecologically relevant species is imperative.

Ribosomal RNAs ( $r R N A$ ) are non-coding RNA molecules that make up the ribosomal complexes involved in translation of messenger RNA into proteins. In eukaryotes, 28S and 18S rRNA molecules typically span lengths of two and four kilobases, respectively (3). They comprise at least $80 \%$ of the total cellular RNA population. In RNA sequencing experiments, their depletion is a necessary step during library preparation where it is not possible to selectively enrich target signals (4). To achieve this, the most common depletion protocols rely on knowledge of rRNA sequence of the species of interest. These involve hybridizing rRNA to antisense oligos (probes or primers) followed by digestion by ribonucleases $(4,5)$ or bead capture $(6)$.

For well-studied mosquito species, reference rRNA sequences are readily available on public sequence databases such as GenBank or SILVA. As conventional knowledge in rDNA holds that rRNA coding regions are conserved across all species, it may seem conceivable to use rRNA oligobased depletion protocols designed for one species on another. However, we found that within the taxon Culicidae this is not always true. There is enough sequence divergence such that Ae. aegyptibased probes produced poor depletion in Culex and Anopheles mosquitoes. In addition, full-length rRNA sequences are much less represented compared to other molecular markers such as the cytochrome c oxidase subunit I (COI) gene, which is the most widely used molecular barcode for animals $(7,8)$. The lack of reliable rRNA depletion methods could deter metagenomic studies from expanding their sampling diversity. This narrows our knowledge of mosquito ecology to urbandwelling species when forest-dwelling mosquitoes are the ones responsible for maintaining the sylvatic transmission of arboviruses among their reservoir hosts, which precedes autochthonous transmission in human populations (9).

To address this, we sought to determine the $28 \mathrm{~S}$ and 18S rRNA sequences of a diverse set of sylvatic mosquito species across the Central African Republic, Madagascar, Cambodia, and French Guiana. We employed a unique score-based read filtration strategy to remove contaminating nonmosquito rRNA reads to ensure accurate de novo assembly and generated $12028 \mathrm{~S}$ and $11218 \mathrm{~S}$ sequences from 29 mosquito species. In parallel, we obtained $\mathrm{COI}$ sequences to validate morphology-based species identification and to compare phylogenetic relationships inferred from the 
three molecular markers. Our findings suggest the possibility of using $28 \mathrm{~S}$ and $18 \mathrm{~S}$ rRNA sequences as "RNA barcodes". This work makes possible the use of rRNA sequences for streamlined molecular species identification during RNAseq, facilitates the assembly of more rRNA sequences to expand the rRNA reference library, and enables the design of species-specific oligos for cost-effective rRNA depletion.

\section{MATERIAL AND METHODS}

\section{Sample collection}

Mosquito specimens were sampled during 2019-2020 by medical entomology teams from Institut Pasteur de Bangui (Central African Republic; CF), Institut Pasteur du Cambodge (Cambodia; KH), Institut Pasteur de Madagascar (Madagascar; MG), and Institut Pasteur de la Guyane (French Guiana; GF). Adult mosquitoes were sampled using a combination of techniques including CDC light traps, BG sentinels, and human-landing catches. Sampling sites represent non-urban locations including rural settlements (Central African Republic, Madagascar, and French Guiana) and national parks (Cambodia). Mosquitoes were identified using morphological identification keys on cold tables before preserved at $-80^{\circ} \mathrm{C}$ and transported in cold chain to Institut Pasteur Paris for analysis. The full list of the 112 mosquito specimens used in this study and their related information are provided in Supplementary Table 1.

\section{RNA and DNA isolation}

Nucleic acids were isolated from mosquito specimens using the TRlzol reagent according to manufacturer's protocol (Invitrogen, Thermo Fisher Scientific, Waltham, Massachusetts, USA, Cat. No. 15596018). Single mosquitoes were homogenized into $200 \mu \mathrm{L}$ of TRIzol reagent and the rest of the reagents within the protocol were volume-adjusted accordingly. Following phase separation, RNA samples were isolated from the aqueous phase while DNA was isolated from the remaining interphase and phenol-chloroform phases. From here, RNA is used to prepare cDNA libraries for next generation sequencing and DNA is used for PCR amplification and Sanger sequencing of the mitochondrial cytochrome c oxidase subunit I (COI) gene.

\section{Total RNA sequencing}

To obtain rRNA sequences, RNA samples were quantified on a Qubit Fluorometer (Invitrogen) using the Qubit RNA BR Assay kit (Invitrogen, Cat No. Q10211) for concentration adjustment. Total RNA was used for library preparation for next generation sequencing using the NEBNext Ultra II RNA Library Preparation Kit for Illumina (New England Biolabs, Ipswich, Massachusetts, USA, Cat. No. E7770L) and the NEBNext Multiplex Oligos for Illumina (Dual Index Primers Set 1) (New England Biolabs, Cat. No. E7600S). Sequencing was performed on a NextSeq500 sequencing system (Illumina, San Diego, California, USA). Quality control of fastq data and trimming of adapters were performed with FastQC and cutadapt, respectively.

\section{$28 \mathrm{~S}$ and $18 \mathrm{~S}$ rRNA assembly}


To obtain $28 \mathrm{~S}$ and $18 \mathrm{~S}$ rRNA contigs, we had to first clean our fastq library by separating the reads representing mosquito rRNA from all other reads. To achieve this, we used the SILVA sequence database to create 2 libraries: one containing all rRNA sequences recorded under the "Insecta" node of the taxonomic tree, the other containing the rRNA sequences of many others nodes distributed throughout the taxonomic tree, hence named "Non-Insecta" (10). Each read was aligned using the nucleotide Basic Local Alignment Search Tool (BLASTn, https://blast.ncbi.nlm.nih.gov/) of the National Center for Biotechnology Information (NCBI) against each of the two libraries and the scores of the best high-scoring pairs from the two BLASTns are subsequently used to calculate a ratio of Insecta over Non-Insecta scores (11). Only reads with a ratio greater than 0.8 were used in the assembly. The two libraries being non-exhaustive, we chose this threshold of 0.8 to eliminate only reads that were clearly of a non-insect origin. Selected reads were assembled with the SPAdes assembler using the "-rna" option, allowing more heterogeneous coverage of contigs and kmer lengths of 31,51 and 71 bases (12). This method successfully assembled rRNA sequences for all specimens (120 sequences for $28 \mathrm{~S}$ and 112 sequences for $18 \mathrm{~S}$ ).

Initially, our filtration technique had two weaknesses. First, there is a relatively small number of complete rRNA sequences in the Insecta library from SILVA. To compensate for this, we carried out several filtration cycles and in between cycles, added all the complete sequences produced in previous cycles to the Insecta library. Second, when our mosquito specimens were parasitized by other insects, it was not possible to bioinformatically filter out rRNA reads belonging to the parasite. For these rare cases, we used the "--trusted-contigs" option of SPAdes, giving it access to the $28 \mathrm{~S}$ and $18 \mathrm{~S}$ sequences of the mosquito closest in terms of taxonomy to the one we were assembling. By doing this, the assembler was able to reconstruct the rRNA of the mosquito as well as the rRNA of the parasitizing insect.

\section{COI amplicon sequencing}

The mitochondrial COI gene was amplified from DNA samples using the primer set LCO1490 (5'GGTCAACAAATCATAAAGATATTGG -3') and HCO2198 (5'-

TAAACTTCAGGGTGACCAAAAAATCA-3'), as is the standard for COI barcoding, producing a $658 \mathrm{bp}$ product (13). PCRs were performed using Phusion High-Fidelity DNA Polymerase (Thermo Fisher Scientific, Cat. No. F530L). Every $50 \mu \mathrm{L}$ reaction contained $10 \mu \mathrm{L}$ of $5 \mathrm{X}$ High Fidelity buffer, $1 \mu \mathrm{L}$ of 10 $\mathrm{mM}$ dNTPs, $2.5 \mu \mathrm{L}$ each of $10 \mathrm{mM}$ forward (LCO1490) and reverse (HCO2198) primer, $28.5 \mu \mathrm{L}$ of water, $5 \mu \mathrm{L}$ of DNA sample, and $0.5 \mu \mathrm{L}$ of $2 \mathrm{U} / \mu \mathrm{L}$ Phusion DNA polymerase. A 3-step cycling incubation protocol was used: $98^{\circ} \mathrm{C}$ for 30 seconds; 35 cycles of $98^{\circ} \mathrm{C}$ for 10 seconds, $60^{\circ} \mathrm{C}$ for 30 seconds, and $72{ }^{\circ} \mathrm{C}$ for 15 seconds; $72{ }^{\circ} \mathrm{C}$ for 5 minutes followed by a $4{ }^{\circ} \mathrm{C}$ hold. PCR products were verified to be of the correct size using gel electrophoresis and then purified from gel cut-outs using the QIAquick Gel Extraction Kit (Qiagen, Hilden, Germany, Cat. No. 28706). Sanger sequencing of the COI amplicons were performed by Eurofins Genomics, Ebersberg, Germany. 


\section{COI sequence analysis}

Forward and reverse COI DNA sequences were end-trimmed to remove bases of poor quality ( $Q$ score < 30). At the 5 ' ends, sequences were trimmed at the same positions such that all forward sequences start with 5'- TTTTGG and all reverse sequences start with 5'- GGNTCT. Forward and reverse sequences were aligned using BLAST to produce a $621 \mathrm{bp}$ consensus sequence, the minimum length of $\mathrm{COI}$ sequence obtained for all specimens. In cases where good quality sequences extends beyond $621 \mathrm{bp}$, forward and reverse sequences were assembled using Pearl (https://www.gear-genomics.com/pearl/) and manually checked for errors against trace files (14, 15). A total of 106 sequences were successfully assembled.

Assembled COI sequences were analyzed with BLASTn against the nucleotide collection ( $\mathrm{nr} / \mathrm{nt})$ database to validate morphology-based species identification. In cases where the COI-based and morphology-based species identification disagree, the species identity indicated by the $\mathrm{COI}$ sequence is taken to be the true identity when the algorithm returns references of a single species with nucleotide similarities of $>95 \%$ relative to the query sequence. In cases where matches were found within a single genus but with multiple species, specimens were indicated as an unknown member of their genus (e.g. Culex sp.). In cases where COI BLASTn could not reveal an unequivocal match, species identity remained as indicated by its morphology. Information of the top-scoring references for all specimens, including details of ambiguous BLASTn results, are recorded in Supplementary Table 2. All assembled COI sequences from this study are to be deposited in GenBank.

\section{Phylogenetic analysis}

Multiple sequence alignment (MSA) were performed on assembled COI and rRNA sequences using the MUSCLE software (Supplementary Data 1-4) $(16,17)$. As shown in Supplementary Figure 1 on the conservation of identity along the alignment, the $28 \mathrm{~S}$ sequences contain many blocks of highly conserved nucleotides throughout the sequence, which makes the result of the multiple alignment particularly obvious. We therefore did not test other alignment programs. The multiple alignment of the $\mathrm{COI}$ amplicon is even more evident since no gaps are necessary for this alignment.

Phylogenetic reconstruction was performed with the MEGA X software using the maximumlikelihood method (18). The default parameters were used in addition to performing bootstrapping with 500 replications in order to be able to quantify the level of confidence in the branches of the trees obtained. For the $28 \mathrm{~S}$ and $18 \mathrm{~S}$ rRNA trees, two sequences belonging to an unknown species of parasitic mite from the genus Horreolanus found in our specimens were included to serve as an outgroup taxon. In addition, we created and analyzed a separate dataset combining our 28S rRNA sequences and full-length $28 \mathrm{~S}$ rRNA sequences from the NCBI databases totaling 169 sequences from 58 species ( 12 subgenera). The sequences and their accession numbers corresponding to a specimen ID (S\#, where \# is an ID number) can be found in Supplementary Table 1. 
bioRxiv preprint doi: https://doi.org/10.1101/2022.02.01.478639; this version posted February 3, 2022. The copyright holder for this preprint (which was not certified by peer review) is the author/funder, who has granted bioRxiv a license to display the preprint in perpetuity. It is made available under aCC-BY-NC 4.0 International license.

\section{RESULTS}

\section{Poor rRNA depletion using non-specific depletion methods}

In library preparations of mosquito samples for RNAseq, the most common methods for depleting rRNA are commercial kits optimized for human or mice samples (19-24) or probe hybridization followed by ribonuclease digestion where the probes are 80-100 base pair antisense oligos. In cases where the reference rRNA sequence of the target species is not known, oligos would be designed based on the rRNA sequence of the closest related species (25, this study). These methods should be able to produce acceptable rRNA depletion efficiencies due to the assumption that rRNA sequences have high degrees of homology across taxa. However, in our hands we found that using probes designed for the Ae. aegypti rRNA sequence followed by RNase $\mathrm{H}$ digestion according to the protocol published by Morlan et al. (26) produced poor depletion in Ae. albopictus, and even more so in Culicine and Anopheline species (Figure 1A). Additionally, not knowing the relevant reference rRNA sequences compromises the cleanup of remaining rRNA reads from sequencing data, as reads belonging to more divergent regions may not map to a reference sequence from a different species. To solve this and to improve future RNAseq metagenomics, we sought to obtain reference rRNA sequences for 29 mosquito species across nine genera that are associated with vector activity for various pathogens (Table 1).

Table 1. List of mosquito species represented in this study and their vector status.

\begin{tabular}{|c|c|c|c|c|}
\hline Mosquito taxonomy* & Origin $^{* *}$ & Collection site & Vector for ${ }^{\star * *}$ & Reference \\
\hline Aedes (Fredardsius) vittatus & $\mathrm{CF}$ & rural (village) & DENV, ZIKV, CHIKV, YFV & (27) \\
\hline Aedes (Ochlerotatus) scapularis & GF & rural (village) & YFV & (28) \\
\hline Aedes (Ochlerotatus) serratus & GF & rural (village) & YFV, OROV & $(29,30)$ \\
\hline Aedes (Stegomyia) aegypti & CF & urban & DENV, ZIKV, CHIKV, YFV & (31) \\
\hline Aedes (Stegomyia) albopictus & $\mathrm{CF}, \mathrm{KH}$ & $\begin{array}{l}\text { rural (village, } \\
\text { nature reserve) }\end{array}$ & $\begin{array}{l}\text { DENV, ZIKV, CHIKV, YFV, } \\
\text { JEV }\end{array}$ & $(31,32)$ \\
\hline Aedes (Stegomyia) simpsoni & CF & rural (village) & YFV & (33) \\
\hline Anopheles (Anopheles) baezai & $\mathrm{KH}$ & $\begin{array}{l}\text { rural (nature } \\
\text { reserve) }\end{array}$ & unreported & - \\
\hline Anopheles (Anopheles) coustani & $\mathrm{MG}, \mathrm{CF}$ & rural (village) & RVFV, malaria & $(34-36)$ \\
\hline Anopheles (Cellia) funestus & MG, CF & rural (village) & ONNV, malaria & $(37)$ \\
\hline Anopheles (Cellia) gambiae & MG, CF & rural (village) & ONNV, malaria & (38) \\
\hline Anopheles (Cellia) squamosus & MG & rural (village) & RVFV, malaria & $(36,39)$ \\
\hline $\begin{array}{l}\text { Coquillettidia (Rhynchotaenia) } \\
\text { venezuelensis }\end{array}$ & GF & rural (village) & OROV & $(30)$ \\
\hline Culex (Culex) antennatus & MG & rural (village) & RVFV & $(35,36)$ \\
\hline Culex (Culex) duttoni & CF & rural (village) & unreported & - \\
\hline Culex (Culex) neavei & MG & rural (village) & USUV & $(40)$ \\
\hline Culex (Culex) orientalis & $\mathrm{KH}$ & $\begin{array}{l}\text { rural (nature } \\
\text { reserve) }\end{array}$ & JEV & (41) \\
\hline Culex (Culex) perexiguus & MG & rural (village) & WNV & (42) \\
\hline Culex (Culex) pseudovishnui & $\mathrm{KH}$ & $\begin{array}{l}\text { rural (nature } \\
\text { reserve) }\end{array}$ & JEV & $(32,43)$ \\
\hline Culex (Culex) quinquefasciatus & $\begin{array}{l}\text { MG, CF, } \\
\mathrm{KH}\end{array}$ & $\begin{array}{l}\text { rural (village, } \\
\text { nature reserve) }\end{array}$ & $\begin{array}{l}\text { ZIKV, JEV, WNV, DENV, } \\
\text { SLEV, RVFV, Wuchereria } \\
\text { bancrofti }\end{array}$ & $(43-45)$ \\
\hline Culex (Culex) tritaeniorhynchus & MG, KH & $\begin{array}{l}\text { rural (village, } \\
\text { nature reserve) }\end{array}$ & JEV, WNV, RVFV & $(32,43)$ \\
\hline Culex (Melanoconion) pedroi & GF & rural (village) & EEEV & (46) \\
\hline
\end{tabular}




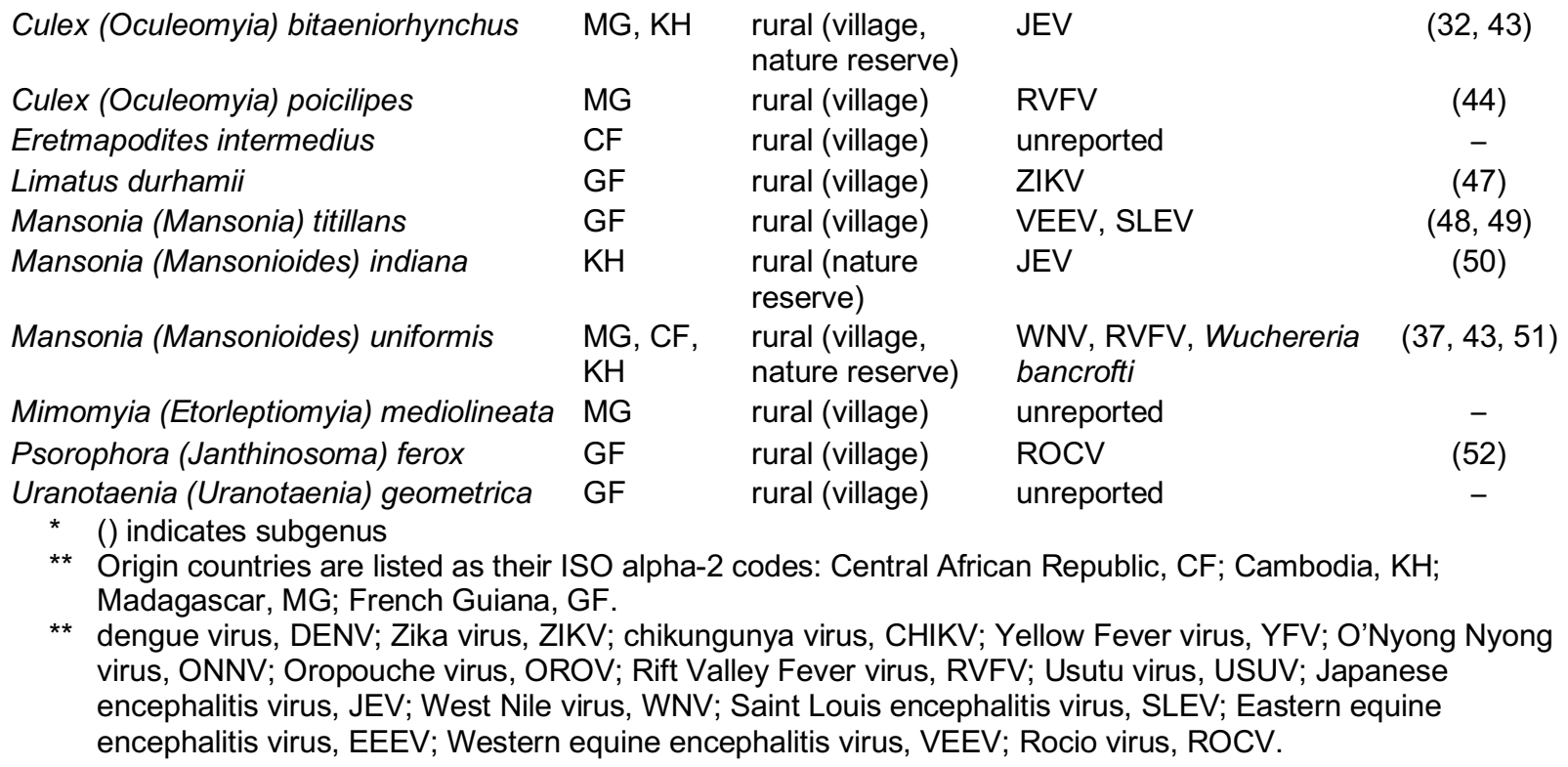

\section{Molecular validation of morphology-based species identification}

To validate morphology-based species identification from the DNA sample of each specimen, the COI gene was amplified by PCR using the LCO1490/HCO2198 primer set. Sequences at least $620 \mathrm{bp}$ long were successfully obtained for 106 specimens. BLAST analyses revealed 32 cases where top hits indicated a different species identity, taking $<95 \%$ nucleotide identity as the threshold to delineate distinct species (Supplementary Table 2). All species names reported hereafter reflect identities as determined by $\mathrm{CO}$ barcoding except for cases where species identity could not be unequivocally determined by the $\mathrm{COI}$ sequence, then the morphology-based identity is retained.

For each case of disagreement in species identity, the COI sequence of the specimen was BLAST aligned against an NCBI entry representing the morphological species to verify that the new identity is a closer match by a significant margin, i.e., more than $2 \%$. Most cases readily met this criterion with a few exceptions, which are noted in Supplementary Table 2. We found that An. coustani COI, regardless of specimen origin, shared remarkably high nucleotide similarity $(>98 \%)$ with several other Anopheles species such as An. rhodesiensis, An. rufipes, An. ziemanni, An. tenebrosus, although An. coustani remained the most frequent and closest match. Several Culex specimens belonging to the $C x$. pipiens or $C x$. vishnui species groups returned ambiguous results as well, where the query sequence differed with either of the top two hits by only one nucleotide. For example, $C x$. quinquefasciatus and $C x$. pipiens of the $C x$. pipiens group, and $C x$ vishnui and $C x$ tritaeniorhynchus of the $C x$ vishnui group.

Three specimens of $A$ e. simpsoni were initially morphologically identified as $A$ e. opok but showed 97-100\% similarity to Ae. simpsoni COI. As NCBI contained no records of Ae. opok COI, we instead aligned the putative Ae. simpsoni $\mathrm{COI}$ sequences against Ae. luteocephalus and Ae. africanus, sister species of $A e$. opok and found they shared only $90 \%$ and $89 \%$ similarity, respectively. Given this divergence, we concluded these specimens to be Ae. simpsoni.

Within our $\mathrm{COI}$ sequences, we found six unidentified Culex species (including two that matched to NCBI entries identified only to the genus level), four unidentified Mansonia species, and one 
unidentified Mimomyia species. For An. baezai, no existing NCBI records were found the the analysis was performed. Thus, our study generated COI sequences for 10 species new to NCBI databases.

\section{rRNA reads filtering and sequence assembly}

Assembling Illumina reads to reconstruct rRNA sequences from total RNA isolated from mosquitoes is not a simple feat. Apart from host rRNA, total RNA samples also contain the rRNA from other organisms associated with the host (microbiota, parasites, or ingested diet). As all of these rRNA sequences contain highly conserved blocks, Illumina reads (150 bp) from these sequences can interfere with and impede the assembly of contigs representing the complete sequences of the $28 \mathrm{~S}$ and $18 \mathrm{~S}$ rRNA of the host.

Our score-based filtration strategy, described in detail under Material and Methods, allowed us to bioinformatically remove contaminating non-mosquito rRNA reads and achieved successful assembly for almost all our specimens. Figure 1B shows how, in a representative sample, the score ratio assigned to each Illumina read allowed us to segregate reads into four categories: (i) reads that map only to the Insecta library, reads that map better to the Insecta relative to Non-Insecta library, (iii) reads that map better to the Non-Insecta relative to the Insecta library, and finally (iv) reads that only map to the Non-Insecta library. By applying a conservative threshold of 0.8 to account for the reference libraries being non-exhaustive, we could filter out reads that do not originate from mosquito rRNA. Given that 15 of our specimens were engorged with vertebrate blood (Supplementary Table 1), this demonstrates that the strategy can perform as expected even with high amounts of contaminating rRNA reads. This is particularly important in studies on field-captured mosquitoes as females are often sampled containing a bloodmeal, or even captured using the human-landing catch technique.

We did encounter challenges for three specimens morphologically identified as Ma. africana (Specimen ID 33-35). COI amplification by PCR failed to produce any product, hence COI barcoding could not be performed to confirm species identity. In addition, SPAdes was only able to assemble partial length contigs, despite the high number of reads with scoring highly against the Insecta library. Amongst other Mansonia specimens, the partial contigs shared the highest similarity with the rRNA sequences of "Ma uniformis CF S51". We then performed a guided assembly using the 28S and $18 \mathrm{~S}$ sequences of this specimen as references, which successfully produced full length contigs. In two of these specimens (Specimen ID 34 and 35), our assembly initially produced two types of 28S and $18 \mathrm{~S}$ rRNA sequences, one of which was similar to mosquito rRNA with low coverage and another with tenfold more coverage and $95 \%$ nucleotide sequence similarity to an Horreolanus species of water mite known to parasitize mosquitoes. Our filtration strategy failed to remove the contaminating reads belonging to the parasite as its taxonomy would have given it a high BLAST score against the Insecta library. However, we were nonetheless able to obtain rRNA sequences for the mosquito as well as the unknown Horreolanus species. This demonstrates that our strategy can be applied to metabarcoding studies where the input material comprises multiple insect species, provided that appropriate reference genomes are available. 
Altogether, we were able to assemble $12028 \mathrm{~S}$ and $11218 \mathrm{~S}$ full-length mosquito rRNA sequences. These sequences represent the first ever record for seven mosquito genera: Coquillettidia, Mansonia, Limatus, Mimomyia, Uranotaenia, Psorophora, and Eretmapodites. As for the Culex, Aedes and Anopheles genera, complete rRNA sequences were already available only for a few species. Our study provides the first record for 18 additional species.
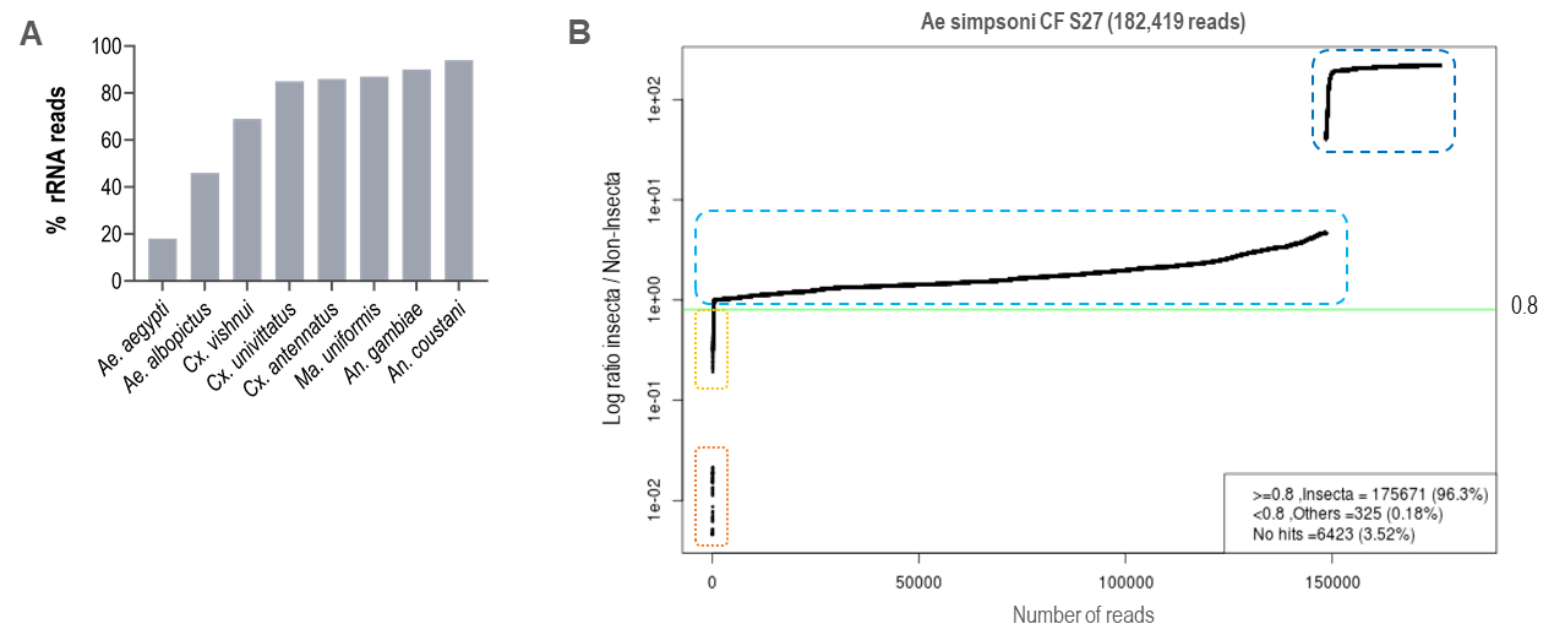

Figure 1. (A) Proportion of rRNA reads found in mosquito specimen pools of 5 individuals depleted by probe hybridization followed by RNase $\mathrm{H}$ digestion. Probes were antisense to Ae. aegypti rRNA sequences. (B) Read vs. score ratio plot of "Ae simpsoni CS S27". Green line indicates 0.8 cut-off where only reads above this threshold are used in rRNA assembly. Dark blue dashed line denotes reads with hits only in the Insecta library. Light blue dashed-line denotes reads with higher-scoring hits in the Insecta library while yellow dotted-line denotes reads with lower-scoring hits In the Insecta library, both relative to the Non-Insecta library. Orange dotted line denotes reads with only hits in the Non-Insecta library.

\section{Discrepancies in 28S, 18S, and COI phylogeny}

To verify our assembly accuracy, we constructed a phylogenetic tree from the $28 \mathrm{~S}$ rRNA sequences generated in our study along with full-length sequences from the NCBI databases (Figure 2). We applied a search criterion for sequences with at least $95 \%$ coverage of our sequence lengths ( 4000 bp), aiming to have as many species as possible represented. This tree showed that our $28 \mathrm{~S}$ sequences clustered correctly within their respective genera with species taxa forming monophyletic clades, apart from An. gambiae, which was depicted to be paraphyletic and shared a common ancestor with An. arabiensis and An. coluzzii.

The rRNA phylogenetic trees benefitted from having Horreolanus serve as an outgroup (Figure 3. $28 \mathrm{~S}$ rRNA, Figure 4. 18S rRNA). Our trees recapitulated what is classically known about the taxonomy of our specimens, namely (i) the division of genus Aedes into subgenera Stegomyia and Ochlerotatus, (ii) the division of genus Culex into subgenera Culex and Melanoconion, (iii) the clustering of Culex sister species according to their species groups, (iv) the early divergence of genus Anopheles from all other genera, $(\mathrm{v})$ the division of genus Anopheles into two subgenera Anopheles 
and Cellia, and (vi) the division of genus Mansonia into subgenera Mansonia and Mansonioides (53) (also see Table 1). This demonstrates the ability of rRNA-based phylogeny to discern taxonomy to the subgenus level. Delineation among species groups is elaborated in a later section.

The $28 \mathrm{~S}$ and $18 \mathrm{~S}$ trees disagree on several points. First, the Culex taxon consist of two branches corresponding to the subgenus Culex and the subgenus Melanoconion. These branches form a paraphyletic taxon in the $28 \mathrm{~S}$ tree, indicating that the common ancestor of the two subgenera branches is also ancestor to the Mansonia (subgenus Mansonioides) clade. In contrast, the Culex taxon was monophyletic in the 18S rRNA tree. Interestingly, the phylogenies of both trees suggest that all Culex specimens originating from French Guiana, including two unknown species, belong to the Melanoconion subgenus. To note, bootstrap values within the Culex (subgenus Culex) branch were generally higher in the $28 \mathrm{~S}$ tree than in the $18 \mathrm{~S}$ tree. Second, both $28 \mathrm{~S}$ and $18 \mathrm{~S}$ trees depict the formation of a Mansonia (subgenus Mansonia) clade comprising "Ma sp.4 GF S103", "Ma sp.4 GF S104", and "Ma titillans GF S105" separate from the Mansonia (subgenus Mansonioides) clade. While the Mansonia taxon at the genus level is almost paraphyletic in the $18 \mathrm{~S}$ tree in that the Mansonia and Culex taxa appeared to share a common ancestor, in the 28S tree the Mansonia (subgenus Mansonia) branch was much more divergent from the Mansonia (subgenus Mansonioides) branch, resulting in a polyphyletic Mansonia taxon. Third, the $28 S$ tree showed the Ps. ferox clade to be most closely related to clade comprising the Aedes and Eretmapodites taxa, which is consistent with the fact that these genera all belong to the Aedini tribe. However, in the $18 \mathrm{~S}$ tree the closest relatives of this clade were the Mansonia (subgenus Mansonioides) clade. Fourth, the Cx. quinquefasciatus specimens were clustered together into a clade in the $28 \mathrm{~S}$ tree but not in the $18 \mathrm{~S}$ tree, suggesting there is higher intraspecies divergence within the 18S rRNA sequences. Likewise, the two Mimomyia specimens, "Mi mediolineata MG S83" from "Mi sp.1 MG S64" formed a monophyletic clade in the $28 \mathrm{~S}$ tree but were a polyphyletic taxon in the $18 \mathrm{~S}$ tree.

Meanwhile, phylogenetic reconstruction based on the $\mathrm{COI}$ sequences showed clustering of generic taxa into clades, except for the Culex and Mansonia genera (Figure 5). The COI phylogeny we obtained here is largely congruent with those from other studies $(54,55)$. Being unrooted, we were unable to make any ancestral observations between taxa. In terms of the five points of differences between the $28 \mathrm{~S}$ and $18 \mathrm{~S}$ trees raised earlier, the $\mathrm{COI}$ tree showed higher congruity to the $28 \mathrm{~S}$ tree than to the $18 \mathrm{~S}$ tree. However, the delineation at the subgenus level for Culex and Mansonia specimens were not as clear. Although the $\mathrm{COI}$ tree does form a Culex (subgenus Culex) clade, the French Guianese specimens were separated between "Cx sp.DJS-2020 GF", which appeared to be more closely related to the Culex (subgenus Culex) clade than to "Cx pedroi GF" and "Cx sp.BTLHVDV-2014". Among the Mansonia specimens, while "Ma sp.4 GF S103", "Ma sp.4 GF S104", and "Ma titillans GF S105" did not cluster with the Mansonia (subgenus Mansonioides) clade as shown in the rRNA trees, their COI sequences did not form a Mansonia (subgenus Mansonia) clade either, instead appearing to be more closely related to species from entirely different genera.

In all rRNA trees, it is clear that the interspecies and intersubgenera evolutionary distances within the genus Anopheles are extremely high compared to any other genera, signifying a greater degree of divergence among its subgenera. This is evident in the longer branch lengths connecting Anopheline 
species clades to the node of the most recent common ancestor for subgenera Anopheles and Cellia (Figures 2-4, Supplementary Figure 2). This feature is not evident in the COI tree, where the Anopheline interspecies distances are comparable to those within the Culex, Aedes, and Mansonia taxa.

We also used $28 \mathrm{~S}$ and $18 \mathrm{~S}$ rRNA sequences for phylogeny-based species identification for six specimens for which COI amplification by PCR was unsuccessful, hence COI barcoding could not be performed. These specimens comprise three unknown Mansonia species (Specimen ID 33-35), a Ma. uniformis (Specimen ID 51), an An. gambiae (Specimen ID 47), and an Ur. geometrica (Specimen ID 113). Their placement in the 28S rRNA tree relative to the other taxa corroborated the morphological identities of all six specimens to the genus level and to the species level for three of them (Figure 3). This was also the case in the 18S tree except for "Ma sp.3 CF S35", which was positioned within the Culex clade (Figure 4). Combined with other discrepancies of the 18S phylogeny mentioned above, it would appear that 28S rRNA sequences and their derived phylogeny are more reliable than $18 \mathrm{~S}$ rRNA sequences for molecular taxonomy.

\section{Culex species groups}

Among our Culex (subgenus Culex) specimens, there are several closely related sister species belonging to the Culex vishnui and Culex univittatus species groups, which are notoriously difficult to differentiate based on morphology. Accordingly, in the $28 \mathrm{~S}$ and $\mathrm{COI}$ trees these species and their known sister species were seen to cluster together in the Culex (subgenus Culex) clade: $C x$. tritaeniorhynchus with $C x$. pseudovishnui and $C x$. perexiguus with $C x$. neavei. Notably, the four unknown Culex species in our study were also positioned in the Culex (subgenus Culex) clade in all trees, indicating they may be sister species to those identified.

The use of $\mathrm{COI}$ barcoding and phylogeny to discern between members of the Culex species groups was successful to a degree for all our specimens but was the least confident for $C x$. tritaeniorhynchus. Our collection includes three $C x$. tritaeniorhynchus individuals from Cambodia and one individual from Madagascar, "Cx tritaeniorhynchus MG S115". In the COI tree, the latter appeared to be more distantly related to the other individuals than $C x$. pseudovishnui is, raising questions as to its species identity. However, the $28 \mathrm{~S}$ and $18 \mathrm{~S}$ tree both placed another $C x$ tritaeniorhynchus specimen as the closest relative to "Cx tritaeniorhynchus MG S115". 
bioRxiv preprint doi: https://doi.org/10.1101/2022.02.01.478639; this version posted February 3, 2022. The copyright holder for this preprint (which was not certified by peer review) is the author/funder, who has granted bioRxiv a license to display the preprint in perpetuity. It is made available under aCC-BY-NC 4.0 International license.

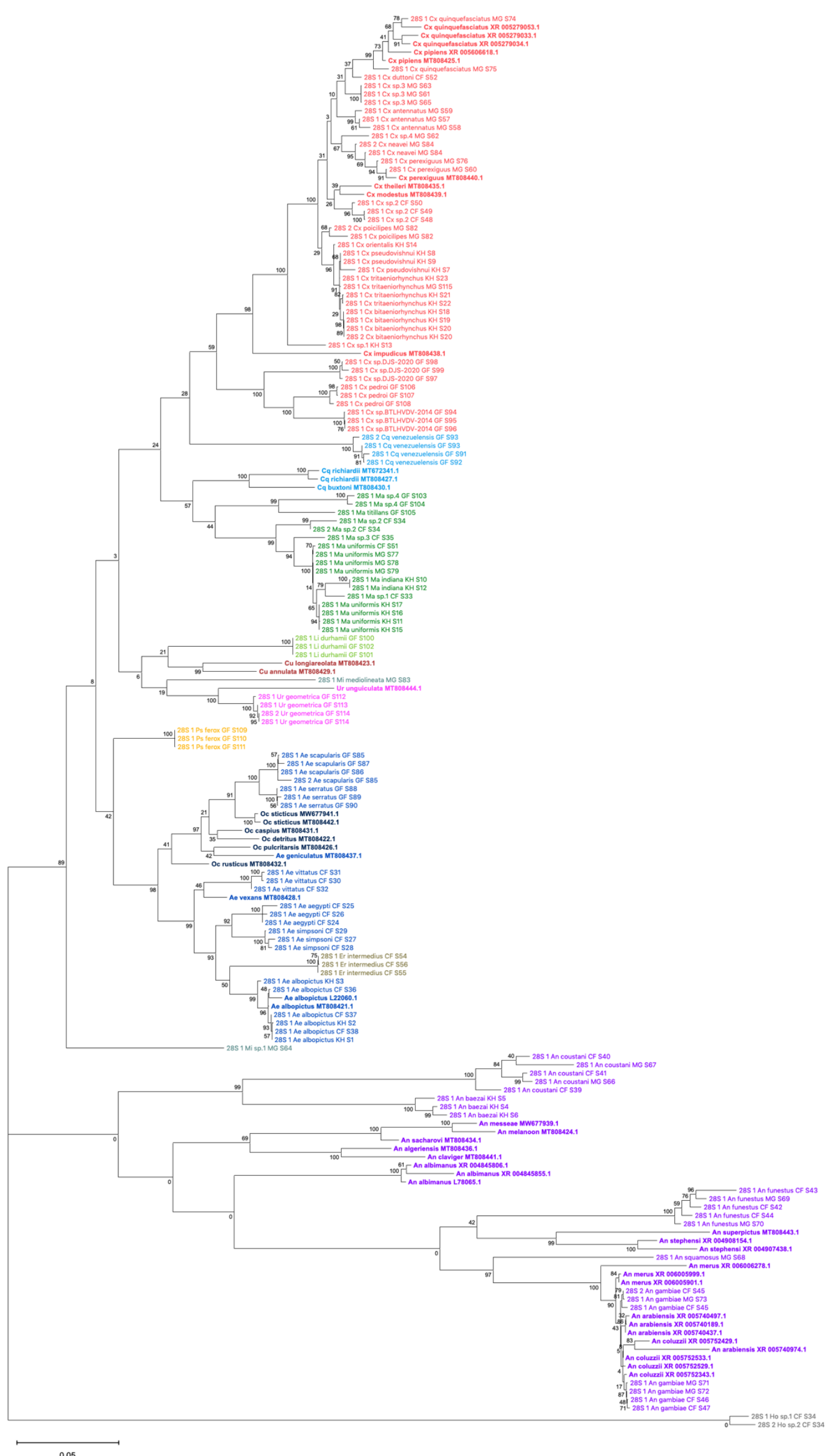


Figure 2. Phylogenetic tree based on $28 \mathrm{~S}$ sequences generated from this study and from NCBI databases combined (3900 bp) as inferred using maximum-likelihood method and constructed to scale in MEGA X (18). Values at each node indicate bootstrap support from 500 replications. For sequences from this study, each specimen label contains information on its taxonomy, origin (as indicated in 2-letter country codes), and specimen ID. Labels in bold indicate sequences derived from NCBI. Label colors indicate genera: Culex in coral, Anopheles in purple, Aedes in dark blue, Mansonia in dark green, Culiseta in maroon, Limatus in light green, Coquillettidia in light blue, Psorophora in yellow, Mimomyia in teal, Uranotaenia in pink and Eretmapodites in brown. Scale bar at 0.05 is shown. 
bioRxiv preprint doi: https://doi.org/10.1101/2022.02.01.478639; this version posted February 3, 2022. The copyright holder for this preprint (which was not certified by peer review) is the author/funder, who has granted bioRxiv a license to display the preprint in perpetuity. It is made available under aCC-BY-NC 4.0 International license.

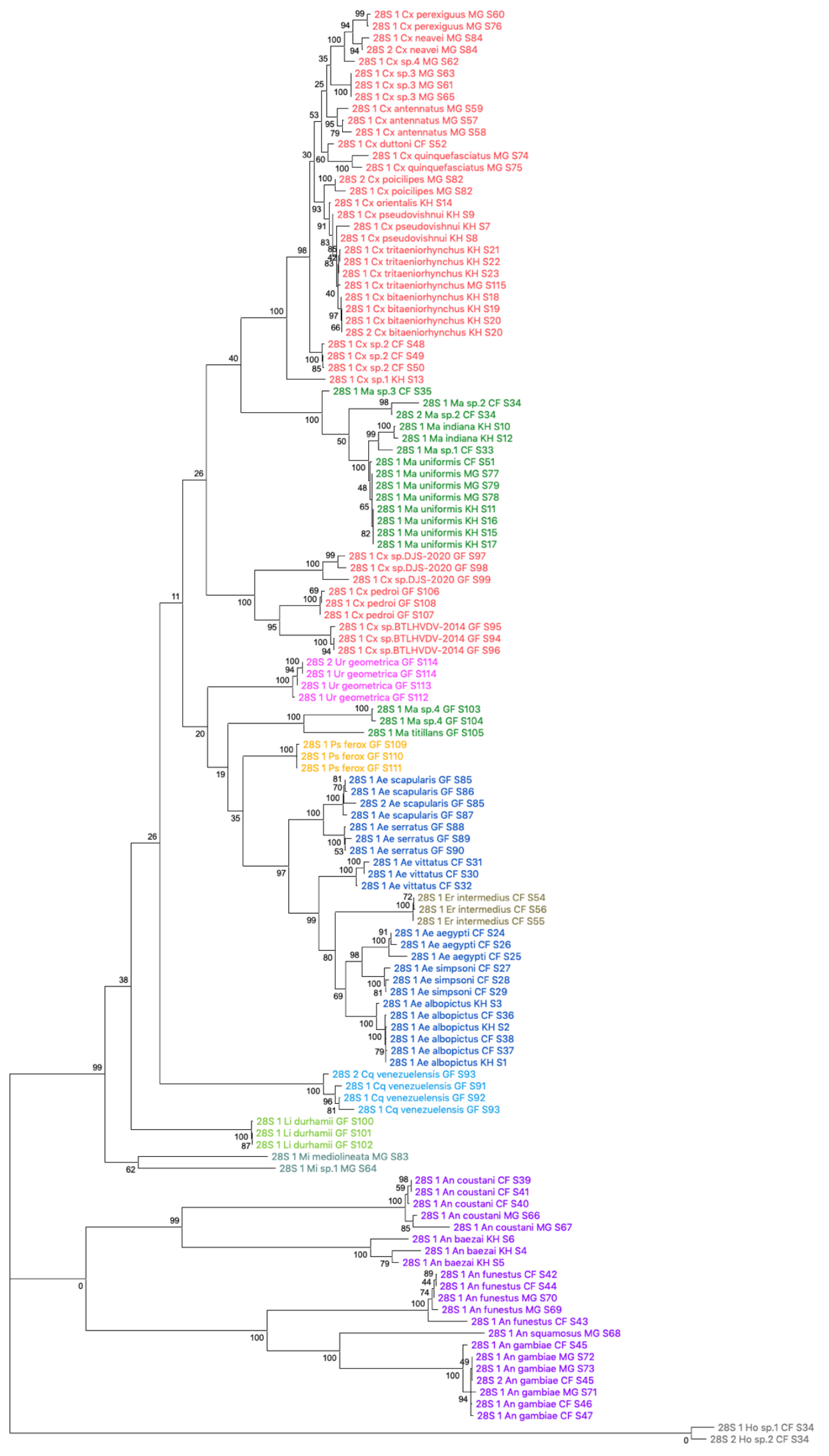


Figure 3. Phylogenetic tree based on $28 \mathrm{~S}$ sequences generated from this study alone ( $3900 \mathrm{bp})$ as inferred using maximum-likelihood method and constructed to scale in MEGA X (18). Values at each node indicate bootstrap support from 500 replication. Each specimen label contains information on its taxonomy, origin (as indicated in 2-letter country codes), and specimen ID. Label colors indicate genera: Culex in coral, Anopheles in purple, Aedes in dark blue, Mansonia in dark green, Limatus in light green, Coquillettidia in light blue, Psorophora in yellow, Mimomyia in teal, Uranotaenia in pink and Eretmapodites in brown. Scale bar at 0.05 is shown. 
bioRxiv preprint doi: https://doi.org/10.1101/2022.02.01.478639; this version posted February 3, 2022. The copyright holder for this preprint (which was not certified by peer review) is the author/funder, who has granted bioRxiv a license to display the preprint in perpetuity. It is made available under aCC-BY-NC 4.0 International license.

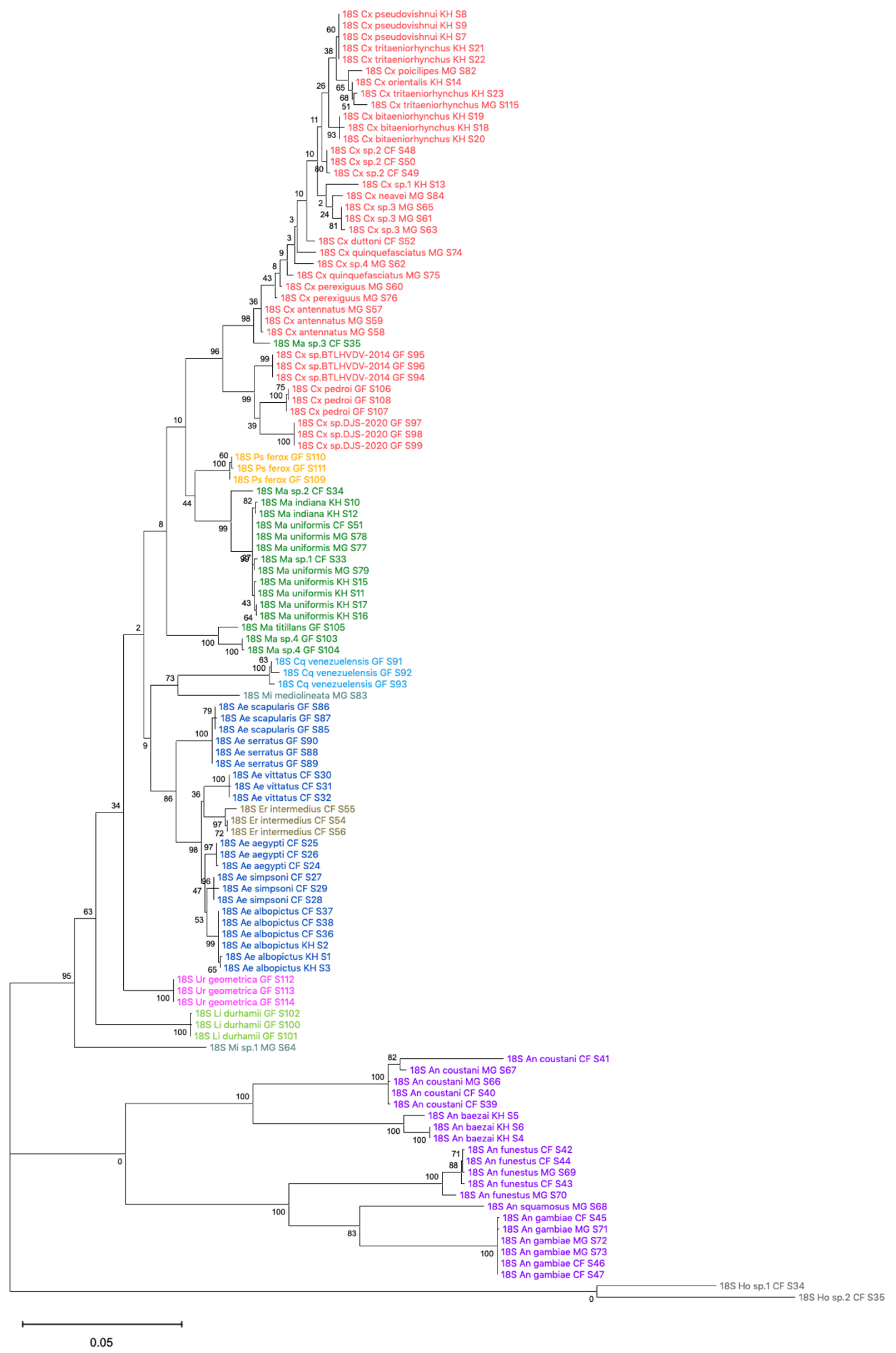


Figure 4. Phylogenetic tree based on $18 \mathrm{~S}$ sequences (1900 bp) as inferred using maximumlikelihood method and constructed to scale in MEGA X (18). Values at each node indicate bootstrap support from 500 replications. Each specimen label contains information on its taxonomy, origin (as indicated in 2-letter country codes), and specimen ID. Label colors indicate genera: Culex in coral, Anopheles in purple, Aedes in dark blue, Mansonia in dark green, Limatus in light green, Coquillettidia in light blue, Psorophora in yellow, Mimomyia in teal, Uranotaenia in pink and Eretmapodites in brown. Scale bar at 0.05 is shown. 
bioRxiv preprint doi: https://doi.org/10.1101/2022.02.01.478639; this version posted February 3, 2022. The copyright holder for this preprint (which was not certified by peer review) is the author/funder, who has granted bioRxiv a license to display the preprint in perpetuity. It is made available under aCC-BY-NC 4.0 International license.

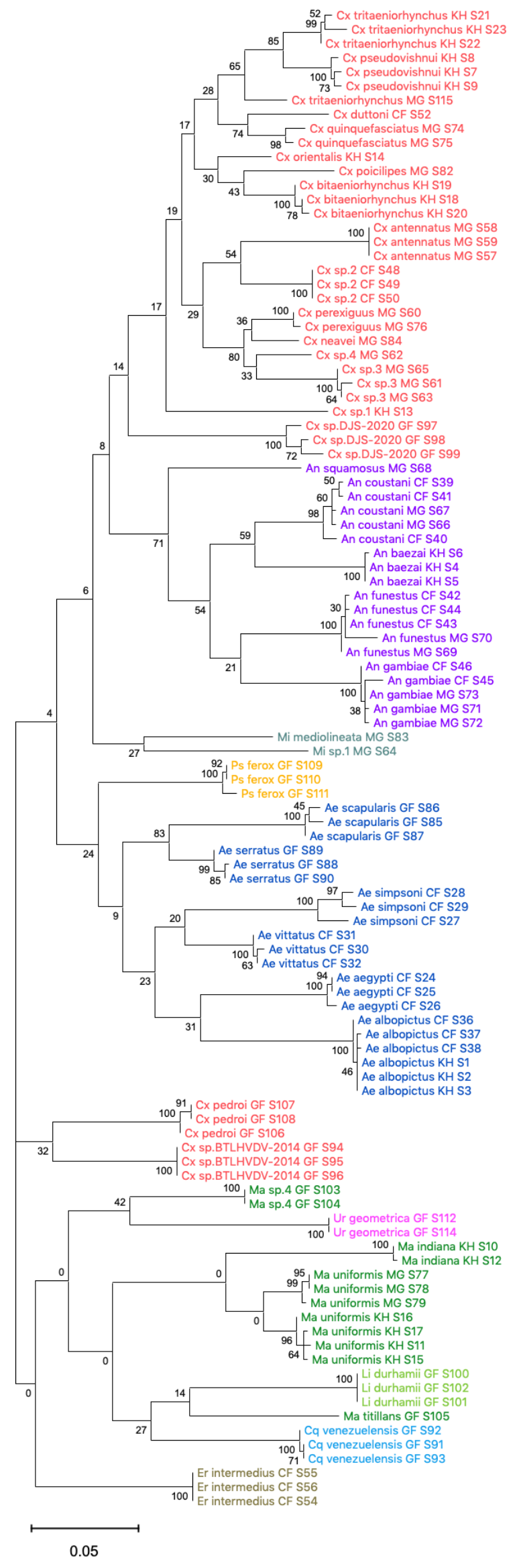


Figure 5. Phylogenetic tree based on $\mathrm{COI}$ sequences (620-699 bp) as inferred using maximumlikelihood method and constructed to scale in MEGA X (18). Values at each node indicate bootstrap support from 500 replications. Each specimen label contains information on its taxonomy, origin (as indicated in 2-letter country codes), and specimen ID. Label colors indicate genera: Culex in coral, Anopheles in purple, Aedes in dark blue, Mansonia in dark green, Limatus in light green, Coquillettidia in light blue, Psorophora in yellow, Mimomyia in teal, Uranotaenia in pink and Eretmapodites in brown. Scale bar at 0.05 is shown. 


\section{DISCUSSION}

Ribosomal RNA has posed a problem in next generation RNAseq since the invention of the technique. In metagenomic studies of field-captured mosquitoes, the lack of reference rRNA sequences hinders oligo-based depletion and efficient cleanup of RNAseq data. Additionally, de novo assembly rRNA sequences is complicated due to the high conservation in rRNA sequences across all distantly related organisms that could be present in a single specimen, i.e., microbiota, parasites, or vertebrate bloodmeal. How can we select for only mosquito reads for assembler input? Our goal in this study was to establish a reliable method to bioinformatically filter contaminating rRNA reads for the accurate assembly of $28 \mathrm{~S}$ and $18 \mathrm{~S}$ rRNA sequences. Further, we compared the phylogenetic reconstructions based on rRNA sequences to that of the mitochondrial COI sequence, a commonly used molecular marker.

We found that phylogenetic trees based on rRNA sequences were able to cluster mosquito taxa according to species correctly. The phylogenetic reconstruction of a combined dataset of the $28 \mathrm{~S}$ rRNA sequences from this study and those already present in the NCBI databases corroborates current mosquito taxonomy knowledge. These demonstrate that our bioinformatics methodology was able to reliably assemble bona fide 28S and 18S rRNA sequences, even in specimens parasitized by water mites or engorged with vertebrate blood. Importantly, we were able to use 28S rRNA phylogeny to perform molecular species identification when $\mathrm{COI}$ sequences were unavailable or ambiguous. We thus propose the use of 28S rRNA sequences as an "RNA barcode" that can complement COI barcoding, with the added advantage that in RNAseq studies, 28S rRNA barcoding can be performed from RNA reads and circumvents the need to additionally isolate DNA from specimens. Even after depletion, there are sufficient numbers of reads remaining to assemble complete rRNA contigs (unpublished data).

The topologies of the $28 \mathrm{~S}$ and $18 \mathrm{~S}$ trees differ for two taxa, "Ma sp.3 CF SS35" and "Mi mediolineata MG S83" where the placement within the $28 \mathrm{~S}$ tree is more similar to that within the COI tree. Given that the species of Ma sp. 3 is unknown and there is a lack of representation of Mimomyia species in our phylogeny, it was not possible to investigate further whether this was a specimenspecific occurrence or a true phylogenetic pattern for genus Mimomyia. It may be possible to resolve this and the other discrepancies between $28 \mathrm{~S}$ and $18 \mathrm{~S}$ phylogenies by performing the analysis instead on concatenated $28 \mathrm{~S}+18 \mathrm{~S}$ sequences, given they are in any case encoded by linked genes.

Relying on morphological markers for species identification has its limits when it comes to Culex species groups. Aside from sharing many morphological traits, sister species within these Culex species groups are often sympatric and show at least some competence for a number of viral and filarial pathogens, such as Japanese encephalitis virus, St Louis encephalitic virus, Usutu virus, and Wuchereria bancrofti (56). However, each of these species have distinct bionomics and host preferences, thus the challenge of correctly identifying vector species can cloud epidemiological risk estimation for these diseases (57).

The $C x$. pipiens group is especially challenging as its member species have been shown to interbreed and produce hybrids, showing genetic introgression to varying extents depending on the geographical location (11). The seven member species of this complex are practically 
indistinguishable morphologically and require molecular methods to discern $(57,58)$. However, the $621 \mathrm{bp} \mathrm{COI}$ sequence does not contain enough nucleotide divergence to allow clear identification, as seen in this study where the $\mathrm{COI}$ of $C x$. quinquefasciatus specimens differ from the $\mathrm{COI}$ of $C x$. pipiens by only one nucleotide. Other DNA molecular markers such as nuclear Ace-2 or CQ11 genes $(58,59)$ or Wolbachia pipientis infection status (60) are typically employed in tandem. This problem of cryptic sister species also permeates the $C x$. vishnui group. The morphological differences between the Culex species bitaeniorhynchus, tritaeniorhynchus, vishnui, and pseudovishnui are thin, the former three having been morphologically detected in our study but later revealed by COI barcoding to be a different species. Here, we used $28 \mathrm{~S}$ and $18 \mathrm{~S}$ phylogenies to resolve an ambiguity in the COI barcoding of a Cx. tritaeniorhynchus specimen, "Cx tritaeniorhynchus MG S115". The combination of $28 \mathrm{~S}$ and 18S rRNA sequences, being longer, contain enough resolution in nucleotide divergence to distinguish between these cryptic species. This should allow for more accurate species identification and, therefore, bionomics in the context of disease transmission. Additionally, tracing the genetic flow across hybrid populations within the $C x$. pipiens species group can inform estimates of vectorial capacity for each species. Only one or two members from the $C x$. pipiens and $C x$. vishnui species groups were represented in our dataset. A focused investigation including all member species of a species group in greater sample numbers is warranted to test the degree of accuracy with which $28 \mathrm{~S}$ and 18S rRNA sequences can delineate sister species and how this compares to COI barcoding.

The world of Anopheles is much wider compared to any other genera. Our $28 \mathrm{~S}$ and $18 \mathrm{~S}$ rRNA phylogenies showed remarkably high divergence between one Anopheline species to another. This feature is not observed in the $\mathrm{COI}$ phylogeny, perhaps reflecting differences in the mutation accumulation rate in the Anopheline nuclear genome to the mitochondrial genome. This may lead to an underestimation of Anopheline species relatedness and suggests that 28S and 18S rRNA sequences, like rDNA sequences, are better able to illustrate evolutionary history than $\mathrm{COI}$ sequence. It would be interesting to further explore divergence among other Anopheline subgenera beyond the subgenera Anopheles and Cellia represented in this study. We also stress the importance of noting detailed taxonomy of mosquito specimens when reporting sequence data when it comes to mosquitoes as we found that many Anopheline rRNA entries lack subgenus information.

We intend for the rRNA sequences presented in this study to improve metagenomic studies of mosquitoes by facilitating the optimization of species-specific oligo-based depletion protocols and by providing reference sequences for species identification by "rRNA barcoding" and for RNAseq data cleanup. The mosquito metagenomics community could benefit from the sharing of more mosquito rRNA sequences on public databases, which would also reveal in time how the rRNA-based phylogenies measure up against other more widely used DNA barcoding markers, such as mitochondrial $\mathrm{COI}$ or $16 \mathrm{~S}$ rDNA and the ribosomal internal transcribed region $2(8,61)$.

\section{Conclusions}

Surveillance and microbiome discovery studies in wild mosquitoes are paramount for the establishment of measures to prepare for and prevent outbreaks of arboviral diseases. The assembly strategy and 232 new $28 S$ and $18 S$ mosquito rRNA sequences we report in this work make future 
RNAseq-based metagenomics on a wider range of mosquito species and other insects achievable by allowing for improved depletion protocols and streamlined species identification from RNA reads. With a large enough reference library, 28S rRNA sequences can serve as a complementary "RNA barcode" for taxonomic and phylogenetic investigations alongside established DNA barcodes. We have already shown here that 28S rRNA phylogenetic tree shares a high degree of congruity with that of $\mathrm{COI}$ and can be used in place of $\mathrm{COI}$ barcoding for species identification. Our work has expanded the rRNA reference library by presenting, to our knowledge, the first records for many species not previously present in public databases and has paved the way for the assembly of many more.

\section{AVAILABILITY}

RNAseq fastq sequence data are available upon request. Multiple sequence alignment files are available as supplementary data.

\section{ACCESSION NUMBERS}

All sequences generated in this study (rRNA and $\mathrm{COI}$ gene sequences) will be submitted to GenBank.

\section{SUPPLEMENTARY DATA}

Supplementary Table 1. Taxonomic and sampling information on mosquito specimens and associated accession numbers for $28 \mathrm{~S}, 18 \mathrm{~S}$, and $\mathrm{COI}$ sequences.

Supplementary Table 2. BLAST analyses summary on COI sequences.

Supplementary Figure 1. Sequence conservation among 169 28S rRNA sequences obtained from this study and from the NCBI databases.

Supplementary Figure 2. Phylogenetic tree based on $28 \mathrm{~S}$ sequences generated from this study and from NCBI databases combined (3900 bp) as inferred using maximum-likelihood method and constructed to scale in MEGA X in radial format (18). Values at each node indicate bootstrap support from 500 replications. For sequences from this study, each specimen label contains information on its taxonomy, origin (as indicated in 2-letter country codes), and specimen ID. Labels in bold indicate sequences derived from NCBI. Label colors indicate genera: Culex in coral, Anopheles in purple, Aedes in dark blue, Mansonia in dark green, Culiseta in maroon, Limatus in light green, Coquillettidia in light blue, Psorophora in yellow, Mimomyia in teal, Uranotaenia in pink and Eretmapodites in brown. Scale bar at 0.05 is shown.

Supplementary Data 1. Multiple sequence alignment of $106 \mathrm{COI}$ sequences.

Supplementary Data 2. Multiple sequence alignment of 114 18S rRNA sequences, including two sequences from Horreolanus sp.

Supplementary Data 3. Multiple sequence alignment of 122 28S rRNA sequences, including two sequences from Horreolanus sp. 
bioRxiv preprint doi: https://doi.org/10.1101/2022.02.01.478639; this version posted February 3,2022 . The copyright holder for this preprint (which was not certified by peer review) is the author/funder, who has granted bioRxiv a license to display the preprint in perpetuity. It is made available under aCC-BY-NC 4.0 International license.

Supplementary Data 4. Multiple sequence alignment of 169 28S rRNA sequences from this study and from NCBI databases.

\section{ACKNOWLEDGEMENT}

We thank members of the Saleh lab for valuable discussions and to Inès Partouche for laboratory assistance. We especially thank all medical entomology staff of IP Bangui, IP Cambodge (Sony Yean, Kimly Heng, Kalyan Chhuoy, Sreynik Nhek, Moeun Chhum, Kimhuor Sour and Pierre-Olivier Maquart), IP Madagascar, and IP Guyane for assistance in field missions, laboratory work, and logistics. We are also grateful to $\mathrm{Dr}$ Catherine Dauga for advice on phylogenetic analyses.

\section{FUNDING}

This work was supported by the Defence Advanced Research Projects Agency PREEMPT program managed by Dr. Rohit Chitale and Dr. Kerri Dugan [Cooperative Agreement HR001118S0017] (the content of the information does not necessarily reflect the position or the policy of the U.S. government, and no official endorsement should be inferred).

\section{CONFLICT OF INTEREST}

The authors declare no conflicts of interest.

\section{REFERENCES}

1. WHO (2017) Global Vector Control Response 2017-2030.

2. Webster,J.P., Gower,C.M., Knowles,S.C.L., Molyneux,D.H. and Fenton,A. (2016) One health - an ecological and evolutionary framework for tackling Neglected Zoonotic Diseases. Evol. Appl., 9, 313-333.

3. GALE,K. and CRAMPTON,J. (1989) The ribosomal genes of the mosquito, Aedes aegypti. Eur. J. Biochem., 10.1111/j.1432-1033.1989.tb15117.x.

4. Phelps,W.A., Carlson,A.E. and Lee,M.T. (2021) Optimized design of antisense oligomers for targeted rRNA depletion. Nucleic Acids Res., 10.1093/nar/gkaa1072.

5. Fauver,J.R., Akter,S., Morales,A.I.O., Black,W.C., Rodriguez,A.D., Stenglein,M.D., Ebel,G.D. and Weger-Lucarelli,J. (2019) A reverse-transcription/RNase $\mathrm{H}$ based protocol for depletion of mosquito ribosomal RNA facilitates viral intrahost evolution analysis, transcriptomics and pathogen discovery. Virology, 528, 181-197.

6. Kukutla,P., Steritz,M. and Xu,J. (2013) Depletion of ribosomal RNA for mosquito gut metagenomic RNA-seq. J. Vis. Exp., 10.3791/50093.

7. Hebert,P.D.N., Cywinska,A., Ball,S.L. and DeWaard,J.R. (2003) Biological identifications through DNA barcodes. Proc. R. Soc. B Biol. Sci., 10.1098/rspb.2002.2218.

8. Ratnasingham,S. and Hebert,P.D.N. (2007) BOLD: The Barcode of Life Data System: Barcoding. Mol. Ecol. Notes, 10.1111/j.1471-8286.2007.01678.x.

9. Gould,E., Pettersson,J., Higgs,S., Charrel,R. and de Lamballerie,X. (2017) Emerging arboviruses: Why today? One Heal., 4, 1-13.

10. Quast,C., Pruesse,E., Yilmaz,P., Gerken,J., Schweer,T., Yarza,P., Peplies,J. and Glöckner,F.O. (2013) The SILVA ribosomal RNA gene database project: Improved data processing and webbased tools. Nucleic Acids Res., 10.1093/nar/gks1219.

11. Altschul,S.F., Gish,W., Miller,W., Myers,E.W. and Lipman,D.J. (1990) Basic local alignment search tool. J. Mol. Biol., 10.1016/S0022-2836(05)80360-2.

12. Bankevich,A., Nurk,S., Antipov,D., Gurevich,A.A., Dvorkin,M., Kulikov,A.S., Lesin,V.M., Nikolenko,S.I., Pham,S., Prjibelski,A.D., et al. (2012) SPAdes: A new genome assembly algorithm and its applications to single-cell sequencing. J. Comput. Biol., 10.1089/cmb.2012.0021. 
bioRxiv preprint doi: https://doi.org/10.1101/2022.02.01.478639; this version posted February 3, 2022. The copyright holder for this preprint (which was not certified by peer review) is the author/funder, who has granted bioRxiv a license to display the preprint in perpetuity. It is made available under aCC-BY-NC 4.0 International license.

13. Folmer,O., Black,M., Hoeh,W., Lutz,R. and Vrijenhoek,R. (1994) DNA primers for amplification of mitochondrial cytochrome c oxidase subunit I from diverse metazoan invertebrates. Mol. Mar. Biol. Biotechnol., 10.1071/ZO9660275.

14. Rausch,T., Fritz,M.H.Y., Untergasser,A. and Benes,V. (2020) Tracy: Basecalling, alignment, assembly and deconvolution of sanger chromatogram trace files. BMC Genomics, 10.1186/s12864-020-6635-8.

15. Rausch,T., Hsi-Yang Fritz,M., Korbel,J.O. and Benes,V. (2019) Alfred: Interactive multi-sample BAM alignment statistics, feature counting and feature annotation for long- and short-read sequencing. Bioinformatics, 10.1093/bioinformatics/bty1007.

16. Madeira,F., Park,Y.M., Lee,J., Buso,N., Gur,T., Madhusoodanan,N., Basutkar,P., Tivey,A.R.N., Potter,S.C., Finn,R.D., et al. (2019) The EMBL-EBI search and sequence analysis tools APIs in 2019. Nucleic Acids Res., 10.1093/nar/gkz268.

17. Edgar,R.C. (2004) MUSCLE: A multiple sequence alignment method with reduced time and space complexity. BMC Bioinformatics, 10.1186/1471-2105-5-113.

18. Kumar,S., Stecher,G., Li,M., Knyaz,C. and Tamura,K. (2018) MEGA X: Molecular evolutionary genetics analysis across computing platforms. Mol. Biol. Evol., 10.1093/molbev/msy096.

19. Bishop-Lilly,K.A., Turell,M.J., Willner,K.M., Butani,A., Nolan,N.M.E., Lentz,S.M., Akmal,A., Mateczun,A., Brahmbhatt,T.N., Sozhamannan,S., et al. (2010) Arbovirus detection in insect vectors by Rapid, high- throughput pyrosequencing. PLoS Negl. Trop. Dis., 10.1371/journal.pntd.0000878.

20. Kumar,N., Creasy,T., Sun,Y., Flowers,M., Tallon,L.J. and Dunning Hotopp,J.C. (2012) Efficient subtraction of insect rRNA prior to transcriptome analysis of Wolbachia-Drosophila lateral gene transfer. BMC Res. Notes, 10.1186/1756-0500-5-230.

21. Weedall,G.D., Irving,H., Hughes,M.A. and Wondji,C.S. (2015) Molecular tools for studying the major malaria vector Anopheles funestus: Improving the utility of the genome using a comparative poly(A) and Ribo-Zero RNAseq analysis. BMC Genomics, 10.1186/s12864-0152114-z.

22. Zakrzewski,M., Rašić,G., Darbro,J., Krause,L., Poo,Y.S., Filipović,I., Parry,R., Asgari,S., Devine,G. and Suhrbier,A. (2018) Mapping the virome in wild-caught Aedes aegypti from Cairns and Bangkok. Sci. Rep., 10.1038/s41598-018-22945-y.

23. Belda,E., Nanfack-Minkeu,F., Eiglmeier,K., Carissimo,G., Holm,I., Diallo,M., Diallo,D., Vantaux,A., Kim,S., Sharakhov,I. V., et al. (2019) De novo profiling of RNA viruses in Anopheles malaria vector mosquitoes from forest ecological zones in Senegal and Cambodia. BMC Genomics, 10.1186/s12864-019-6034-1.

24. Chandler,J.A., Liu,R.M. and Bennett,S.N. (2015) RNA Shotgun Metagenomic Sequencing of Northern California (USA) Mosquitoes Uncovers Viruses, Bacteria, and Fungi. Front. Microbiol., 10.3389/fmicb.2015.00185.

25. Thongsripong,P., Chandler,J.A., Kittayapong,P., Wilcox,B.A., Kapan,D.D. and Bennett,S.N. (2021) Metagenomic shotgun sequencing reveals host species as an important driver of virome composition in mosquitoes. Sci. Rep., 10.1038/s41598-021-87122-0.

26. Morlan,J.D., Qu,K. and Sinicropi,D. V. (2012) Selective depletion of rRNA enables whole transcriptome profiling of archival fixed tissue. PLoS One, 10.1371/journal.pone.0042882.

27. Diallo,D., Fall,G., Diagne,C.T., Gaye,A., Ba,Y., Dia,I., Faye,O. and Diallo,M. (2020) Concurrent amplification of Zika, chikungunya, and yellow fever virus in a sylvatic focus of arboviruses in Southeastern Senegal, 2015. BMC Microbiol., 10.1186/s12866-020-01866-9.

28. Vasconcelos,P.F.C., Costa,Z.G., Travassos da Rosa,E.S., Luna,E., Rodrigues,S.G., Barros,V.L.R.S., Dias,J.P., Monteiro,H.A.O., Oliva,O.F.P., Vasconcelos,H.B., et al. (2001) Epidemic of jungle yellow fever in Brazil, 2000: Implications of climatic alterations in disease spread. J. Med. Virol., 10.1002/jmv.2078.abs.

29. Cardoso,J. da C., de Almeida,M.A.B., dos Santos,E., da Fonseca,D.F., Sallum,M.A.M., Noll,C.A., Monteiro,H.A. d. O., Cruz,A.C.R., Carvalho,V.L., Pinto,E. V., et al. (2010) Yellow fever virus in Haemagogus leucocelaenus and Aedes serratus mosquitoes, Southern Brazil, 2008. Emerg. Infect. Dis., 10.3201/eid1612.100608.

30. Gaillet,M., Pichard,C., Restrepo,J., Lavergne,A., Perez,L., Enfissi,A., Abboud,P., Lambert,Y., Ma,L., Monot,M., et al. (2021) Outbreak of Oropouche Virus in French Guiana. Emerg. Infect. Dis., 10.3201/eid2710.204760.

31. Kraemer,M.U.G., Reiner,R.C., Brady,O.J., Messina,J.P., Gilbert,M., Pigott,D.M., Yi,D., Johnson,K., Earl,L., Marczak,L.B., et al. (2019) Past and future spread of the arbovirus vectors Aedes aegypti and Aedes albopictus. Nat. Microbiol., 10.1038/s41564-019-0376-y.

32. Auerswald,H., Maquart,P.O., Chevalier,V. and Boyer,S. (2021) Mosquito vector competence for 
bioRxiv preprint doi: https://doi.org/10.1101/2022.02.01.478639; this version posted February 3,2022 . The copyright holder for this preprint (which was not certified by peer review) is the author/funder, who has granted bioRxiv a license to display the preprint in perpetuity. It is made available under aCC-BY-NC 4.0 International license.

japanese encephalitis virus. Viruses, 10.3390/v13061154.

33. Mukwaya,L.G., Kayondo,J.K., Crabtree,M.B., Savage,H.M., Biggerstaff,B.J. and Miller,B.R. (2000) Genetic differentiation in the yellow fever virus vector, Aedes simpsoni complex, in Africa:

Sequence variation in the ribosomal DNA internal transcribed spacers of anthropophilic and nonanthropophilic populations. Insect Mol. Biol., 10.1046/j.1365-2583.2000.00161.x.

34. Mwangangi,J.M., Muturi,E.J., Muriu,S.M., Nzovu,J., Midega,J.T. and Mbogo,C. (2013) The role of Anopheles arabiensis and Anopheles coustani in indoor and outdoor malaria transmission in Taveta District, Kenya. Parasites and Vectors, 10.1186/1756-3305-6-114.

35. Nepomichene,T.N.J.J., Raharimalala,F.N., Andriamandimby,S.F., Ravalohery,J.P., Failloux,A.B., Heraud,J.M. and Boyer,S. (2018) Vector competence of Culex antennatus and Anopheles coustani mosquitoes for Rift Valley fever virus in Madagascar. Med. Vet. Entomol., $10.1111 / \mathrm{mve} .12291$.

36. Ratovonjato,J., Olive,M.M., Tantely,L.M., Andrianaivolambo,L., Tata,E., Razainirina,J., Jeanmaire,E., Reynes,J.M. and Elissa,N. (2011) Detection, isolation, and genetic characterization of Rift Valley fever virus from anopheles (Anopheles) coustani, anopheles (Anopheles) squamosus, and culex (Culex) antennatus of the haute matsiatra region, Madagascar. Vector-Borne Zoonotic Dis., 10.1089/vbz.2010.0031.

37. Lutomiah,J., Bast,J., Clark,J., Richardson,J., Yalwala,S., Oullo,D., Mutisya,J., Mulwa,F., Musila,L., Khamadi,S., et al. (2013) Abundance, diversity, and distribution of mosquito vectors in selected ecological regions of Kenya: public health implications. J. Vector Ecol., 38, 134-142.

38. Brault,A.C., Foy,B.D., Myles,K.M., Kelly,C.L.H., Higgs,S., Weaver,S.C., Olson,K.E., Miller,B.R. and Powers,A.M. (2004) Infection patterns of o'nyong nyong virus in the malaria-transmitting mosquito, Anopheles gambiae. Insect Mol. Biol., 10.1111/j.0962-1075.2004.00521.x.

39. Stevenson,J.C., Simubali,L., Mbambara,S., Musonda,M., Mweetwa,S., Mudenda,T., Pringle,J.C., Jones,C.M. and Norris,D.E. (2016) Detection of plasmodium falciparum infection in anopheles squamosus (diptera: Culicidae) in an area targeted for malaria elimination, Southern Zambia. J. Med. Entomol., 10.1093/jme/tjw091.

40. Nikolay,B., Diallo,M., Boye,C.S.B. and Sall,A.A. (2011) Usutu virus in Africa. Vector-Borne Zoonotic Dis., 10.1089/vbz.2011.0631.

41. Kim,H., Cha,G.W., Jeong,Y.E., Lee,W.G., Chang,K.S., Roh,J.Y., Yang,S.C., Park,M.Y., Park,C. and Shin,E.H. (2015) Detection of Japanese encephalitis virus genotype $V$ in Culex orientalis and Culex pipiens (Diptera: Culicidae) in Korea. PLoS One, 10.1371/journal.pone.0116547.

42. Vázquez González,A., Ruiz,S., Herrero,L., Moreno,J., Molero,F., Magallanes,A., SánchezSeco,M.P., Figuerola,J. and Tenorio,A. (2011) West Nile and Usutu viruses in mosquitoes in Spain, 2008-2009. Am. J. Trop. Med. Hyg., 10.4269/ajtmh.2011.11-0042.

43. Maquart,P.O., Sokha,C. and Boyer,S. (2021) Mosquito diversity (Diptera: Culicidae) and medical importance, in a bird sanctuary inside the flooded forest of Prek Toal, Cambodia. J. Asia. Pac. Entomol., 10.1016/j.aspen.2021.08.001.

44. Ndiaye,E.H., Fall,G., Gaye,A., Bob,N.S., Talla,C., Diagne,C.T., Diallo,D., Ba,Y., Dia,I., Kohl,A., et al. (2016) Vector competence of Aedes vexans (Meigen), Culex poicilipes (Theobald) and Cx. quinquefasciatus Say from Senegal for West and East African lineages of Rift Valley fever virus. Parasites and Vectors, 10.1186/s13071-016-1383-y.

45. Bhattacharya,S., Basu,P. and Sajal Bhattacharya,C. (2016) The Southern House Mosquito, Culex quinquefasciatus: profile of a smart vector. J. Entomol. Zool. Stud. JEZS.

46. Turell,M.J., O'Guinn,M.L., Dohm,D., Zyzak,M., Watts,D., Fernandez,R., Calampa,C., Klein,T.A. and Jones,J.W. (2008) Susceptibility of peruvian mosquitoes to eastern equine encephalitis virus. J. Med. Entomol., 10.1603/0022-2585(2008)45[720:SOPMTE]2.0.CO;2.

47. Barrio-Nuevo,K.M., Cunha,M.S., Luchs,A., Fernandes,A., Rocco,I.M., Mucci,L.F., DE Souza,R.P., Medeiros-Sousa,A.R., Ceretti-Junior,W. and Marrelli,M.T. (2020) Detection of Zika and dengue viruses in wildcaught mosquitoes collected during field surveillance in an environmental protection area in São Paulo, Brazil. PLoS One, 10.1371/journal.pone.0227239.

48. Turell,M.J. (1999) Vector competence of three Venezuelan mosquitoes (Diptera: Culicidae) for an epizootic IC strain of Venezuelan equine encephalitis virus. J. Med. Entomol., 10.1093/jmedent/36.4.407.

49. Hoyos-López,R., Soto,S.U., Rúa-Uribe,G. and Gallego-Gómez,J.C. (2015) Molecular identification of saint louis encephalitis virus genotype IV in Colombia. Mem. Inst. Oswaldo Cruz, 10.1590/0074-02760280040.

50. Arunachalam,N., Philip Samuel,P., Hiriyan,J., Thenmozhi,V. and Gajanana,A. (2004) Japanese encephalitis in Kerala, South India: Can Mansonia (Diptera: Culicidae) play a supplemental role in transmission? J. Med. Entomol., 10.1603/0022-2585-41.3.456. 
bioRxiv preprint doi: https://doi.org/10.1101/2022.02.01.478639; this version posted February 3,2022 . The copyright holder for this preprint (which was not certified by peer review) is the author/funder, who has granted bioRxiv a license to display the preprint in perpetuity. It is made available under aCC-BY-NC 4.0 International license.

51. Ughasi,J., Bekard,H.E., Coulibaly,M., Adabie-Gomez,D., Gyapong,J., Appawu,M., Wilson,M.D. and Boakye,D.A. (2012) Mansonia africana and Mansonia uniformis are Vectors in the transmission of Wuchereria bancrofti lymphatic filariasis in Ghana. Parasites and Vectors, 5, 15.

52. Mitchell,C.J., Forattini,O.P. and Miller,B.R. (1986) Vector competence experiments with Rocio virus and three mosquito species from the epidemic zone in Brazil. Rev. Saude Publica, 10.1590/s0034-89101986000300001.

53. Harbach,R.E. (2007) The Culicidae (Diptera): A review of taxonomy, classification and phylogeny. Zootaxa, 10.11646/zootaxa.1668.1.28.

54. Chan,A., Chiang,L.P., Hapuarachchi,H.C., Tan,C.H., Pang,S.C., Lee,R., Lee,K.S., Ng,L.C. and Lam-Phua,S.G. (2014) DNA barcoding: Complementing morphological identification of mosquito species in Singapore. Parasites and Vectors, 10.1186/s13071-014-0569-4.

55. Talaga,S., Leroy,C., Guidez,A., Dusfour,I., Girod,R., Dejean,A. and Murienne,J. (2017) DNA reference libraries of French Guianese mosquitoes for barcoding and metabarcoding. PLoS One, 10.1371/journal.pone.0176993.

56. Nchoutpouen,E., Talipouo,A., Djiappi-Tchamen,B., Djamouko-Djonkam,L., Kopya,E., Ngadjeu,C.S., Doumbe-Belisse,P., Awono-Ambene,P., Kekeunou,S., Wondji,C.S., et al. (2019) Culex species diversity, susceptibility to insecticides and role as potential vector of Lymphatic filariasis in the city of Yaoundé, Cameroon. PLoS Negl. Trop. Dis., 10.1371/journal.pntd.0007229.

57. Farajollahi,A., Fonseca,D.M., Kramer,L.D. and Marm Kilpatrick,A. (2011) 'Bird biting' mosquitoes and human disease: A review of the role of Culex pipiens complex mosquitoes in epidemiology. Infect. Genet. Evol., 10.1016/j.meegid.2011.08.013.

58. Zittra,C., Flechl,E., Kothmayer,M., Vitecek,S., Rossiter,H., Zechmeister,T. and Fuehrer,H.P. (2016) Ecological characterization and molecular differentiation of Culex pipiens complex taxa and Culex torrentium in eastern Austria. Parasites and Vectors, 10.1186/s13071-016-1495-4.

59. Aspen,S. and Savage,H.M. (2003) Polymerase chain reaction assay identifies North American members of the Culex pipiens complex based on nucleotide sequence differences in the acetylcholinesterase gene Ace.2. J. Am. Mosq. Control Assoc.

60. Cornel,A.J., Mcabee,R.D., Rasgon,J., Stanich,M.A., Scott,T.W. and Coetzee,M. (2003) Differences in Extent of Genetic Introgression between Sympatric Culex pipiens and Culex quinquefasciatus (Diptera: Culicidae) in California and South Africa. J. Med. Entomol., 10.1603/0022-2585-40.1.36.

61. Beebe,N.W. (2018) DNA barcoding mosquitoes: Advice for potential prospectors. Parasitology, 10.1017/S0031182018000343.

\section{TABLE AND FIGURES LEGENDS}

Table 1. List of mosquito species represented in this study and their vector status. Origin countries are listed as their ISO alpha-2 codes: Central African Republic, CF; Cambodia, KH; Madagascar, MG; French Guiana, GF.

Figure 1. (A) Proportion of rRNA reads found in mosquito specimen pools depleted by probe hybridization followed by RNase $\mathrm{H}$ digestion. Probes were antisense to Ae. aegypti rRNA sequences.

(B) Read vs. score ratio plot of "Ae simpsoni CS S27". Green line indicates 0.8 cut-off where only reads above this threshold are used in rRNA assembly. Dark blue dashed line denotes reads with hits only in the Insecta library. Light blue dashed-line denotes reads with higher-scoring hits in the Insecta library while yellow dotted-line denotes reads with lower scoring hits In the Insecta library, both relative to the Non-Insecta library. Orange dotted line denotes reads with only hits in the Non-Insecta library.

Figure 2. Phylogenetic tree based on $28 \mathrm{~S}$ sequences generated from this study and from NCBI databases combined (3900 bp) as inferred using maximum-likelihood method and constructed to scale in MEGA X (18). Values at each node indicate bootstrap support from 500 replications. For 
sequences from this study, each specimen label contains information on its taxonomy, origin (as indicated in 2-letter country codes), and specimen ID. Labels in bold indicate sequences derived from NCBI. Label colors indicate genera: Culex in coral, Anopheles in purple, Aedes in dark blue, Mansonia in dark green, Culiseta in maroon, Limatus in light green, Coquillettidia in light blue, Psorophora in yellow, Mimomyia in teal, Uranotaenia in pink and Eretmapodites in brown. Scale bar at 0.05 is shown.

Figure 3. Phylogenetic tree based on $28 \mathrm{~S}$ sequences generated from this study alone (3900 bp) as inferred using maximum-likelihood method and constructed to scale in MEGA X (18). Values at each node indicate bootstrap support from 500 replications. Each specimen label contains information on its taxonomy, origin (as indicated in 2-letter country codes), and specimen ID. Label colors indicate genera: Culex in coral, Anopheles in purple, Aedes in dark blue, Mansonia in dark green, Culiseta in maroon, Limatus in light green, Coquillettidia in light blue, Psorophora in yellow, Mimomyia in teal, Uranotaenia in pink and Eretmapodites in brown. Scale bar at 0.05 is shown.

Figure 4. Phylogenetic tree based on $18 \mathrm{~S}$ sequences (1900 bp) as inferred using maximumlikelihood method and constructed to scale in MEGA X (18). Values at each node indicate bootstrap support from 500 replications. Each specimen label contains information on its taxonomy, origin (as indicated in 2-letter country codes), and specimen ID. Label colors indicate genera: Culex in coral, Anopheles in purple, Aedes in dark blue, Mansonia in dark green, Limatus in light green, Coquillettidia in light blue, Psorophora in yellow, Mimomyia in teal, Uranotaenia in pink and Eretmapodites in brown. Scale bar at 0.05 is shown.

Figure 5. Phylogenetic tree based on $\mathrm{COI}$ sequences (620-699 bp) as inferred using maximumlikelihood method and constructed to scale in MEGA X (18). Values at each node indicate bootstrap support from 500 replications. Each specimen label contains information on its taxonomy, origin (as indicated in 2-letter country codes), and specimen ID. Label colors indicate genera: Culex in coral, Anopheles in purple, Aedes in dark blue, Mansonia in dark green, Limatus in light green, Coquillettidia in light blue, Psorophora in yellow, Mimomyia in teal, Uranotaenia in pink and Eretmapodites in brown. Scale bar at 0.05 is shown. 


\section{SUPPLEMENTARY FIGURES}

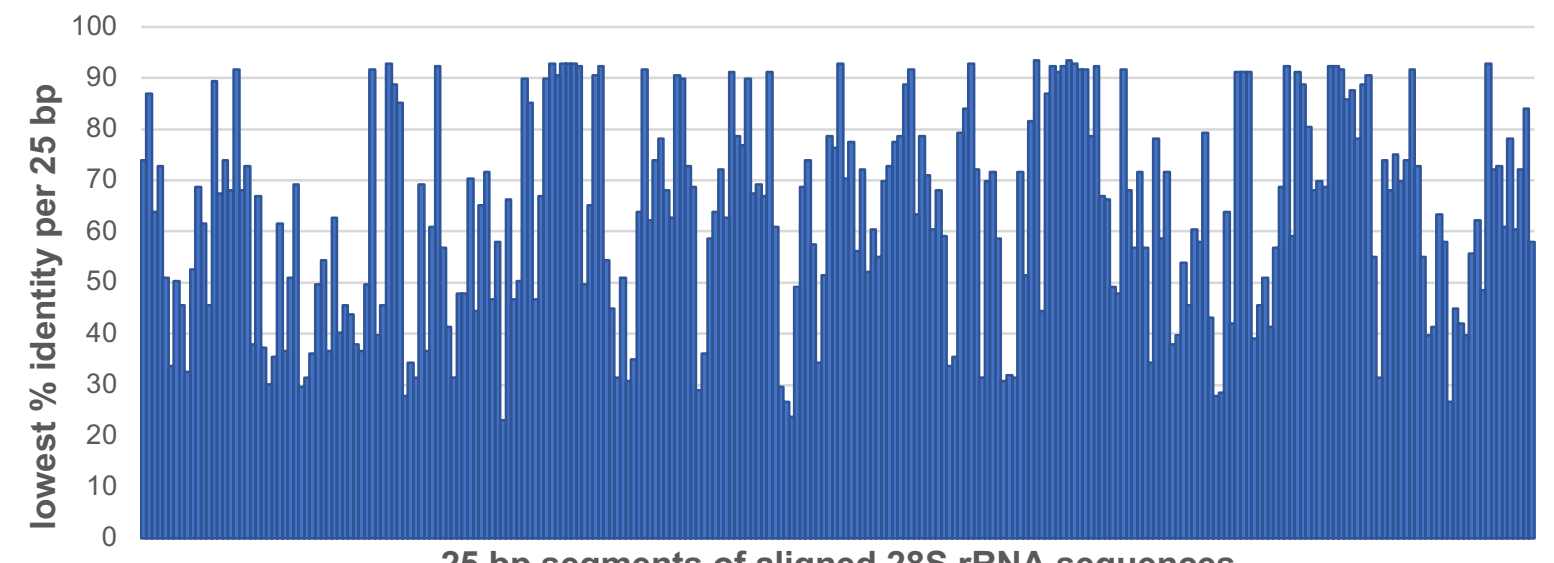

25 bp segments of aligned 28S rRNA sequences

Supplementary Figure 1. Sequence conservation among $16928 \mathrm{~S}$ rRNA sequences from this study and from NCBI databases combined. Multiple sequence alignment was performed on 28S rRNA sequences, $3900 \mathrm{bp}$ in length. Each bar depicts the lowest percentage identity found in every 25-bp segment including gaps in alignment. 


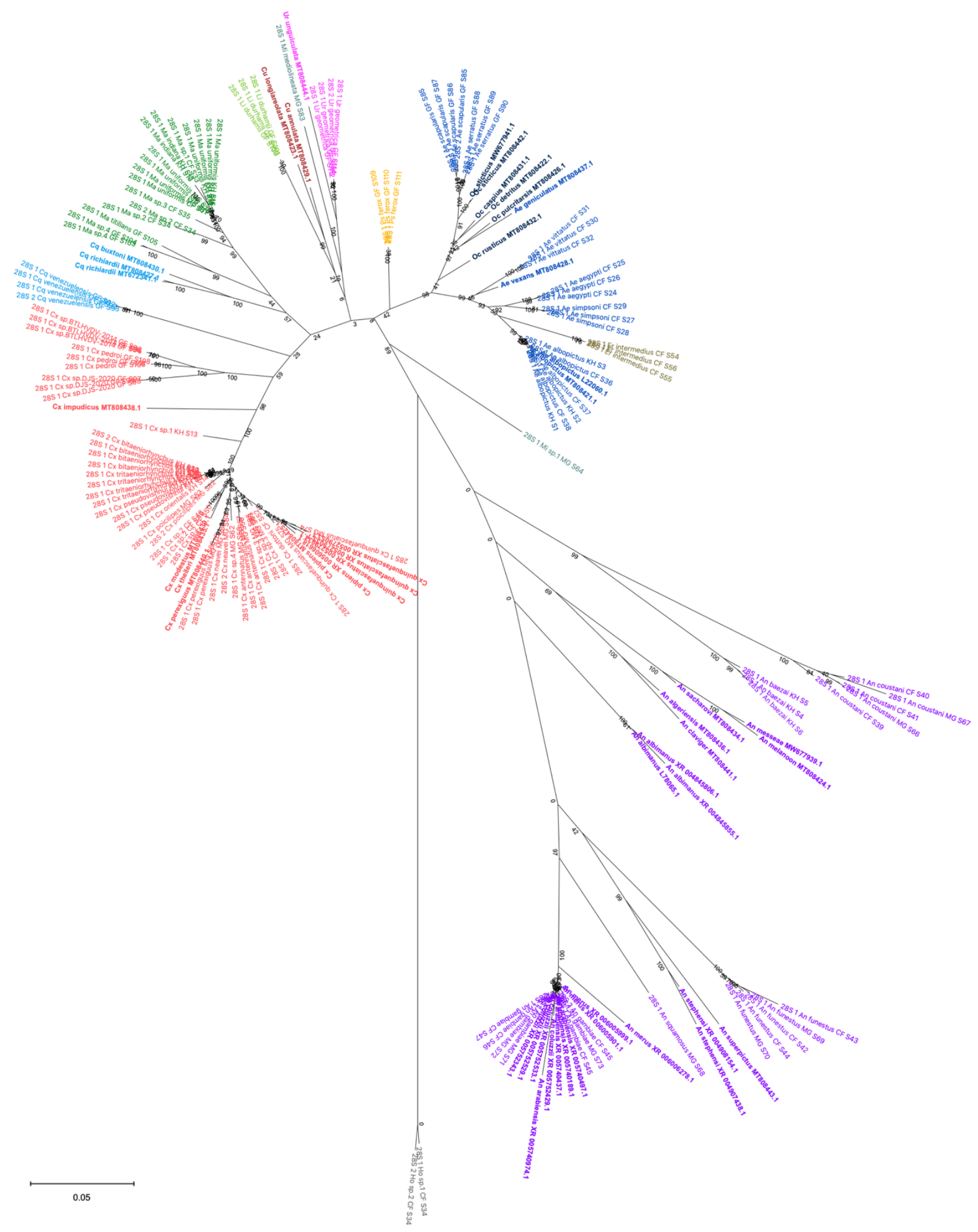

Supplementary Figure 2. Phylogenetic tree based on $28 \mathrm{~S}$ sequences generated from this study and from NCBI databases combined (3900 bp) as inferred using maximum-likelihood method and constructed to scale in MEGA X in radial format (18). Values at each node indicate bootstrap support from 500 replications. For sequences from this study, each specimen label contains information on its taxonomy, origin (as indicated in 2-letter country codes), and specimen ID. Labels in bold indicate sequences derived from NCBI. Label colours indicate genera: Culex in coral, Anopheles in purple, Aedes in dark blue, Mansonia in dark green, Culiseta in maroon, Limatus in light green, Coquillettidia 
bioRxiv preprint doi: https://doi.org/10.1101/2022.02.01.478639; this version posted February 3, 2022. The copyright holder for this preprint (which was not certified by peer review) is the author/funder, who has granted bioRxiv a license to display the preprint in perpetuity. It is made available under aCC-BY-NC 4.0 International license.

in light blue, Psorophora in yellow, Mimomyia in teal, Uranotaenia in pink and Eretmapodites in brown. Scale bar at 0.05 is shown. 


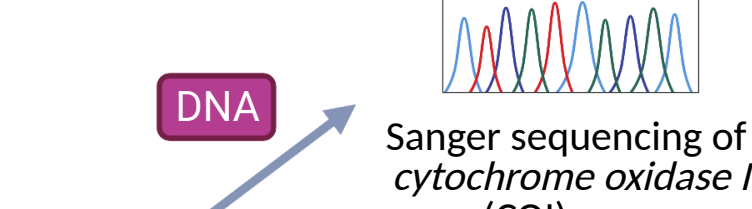
cytochrome oxidase

$$
\text { (COI) gene }
$$

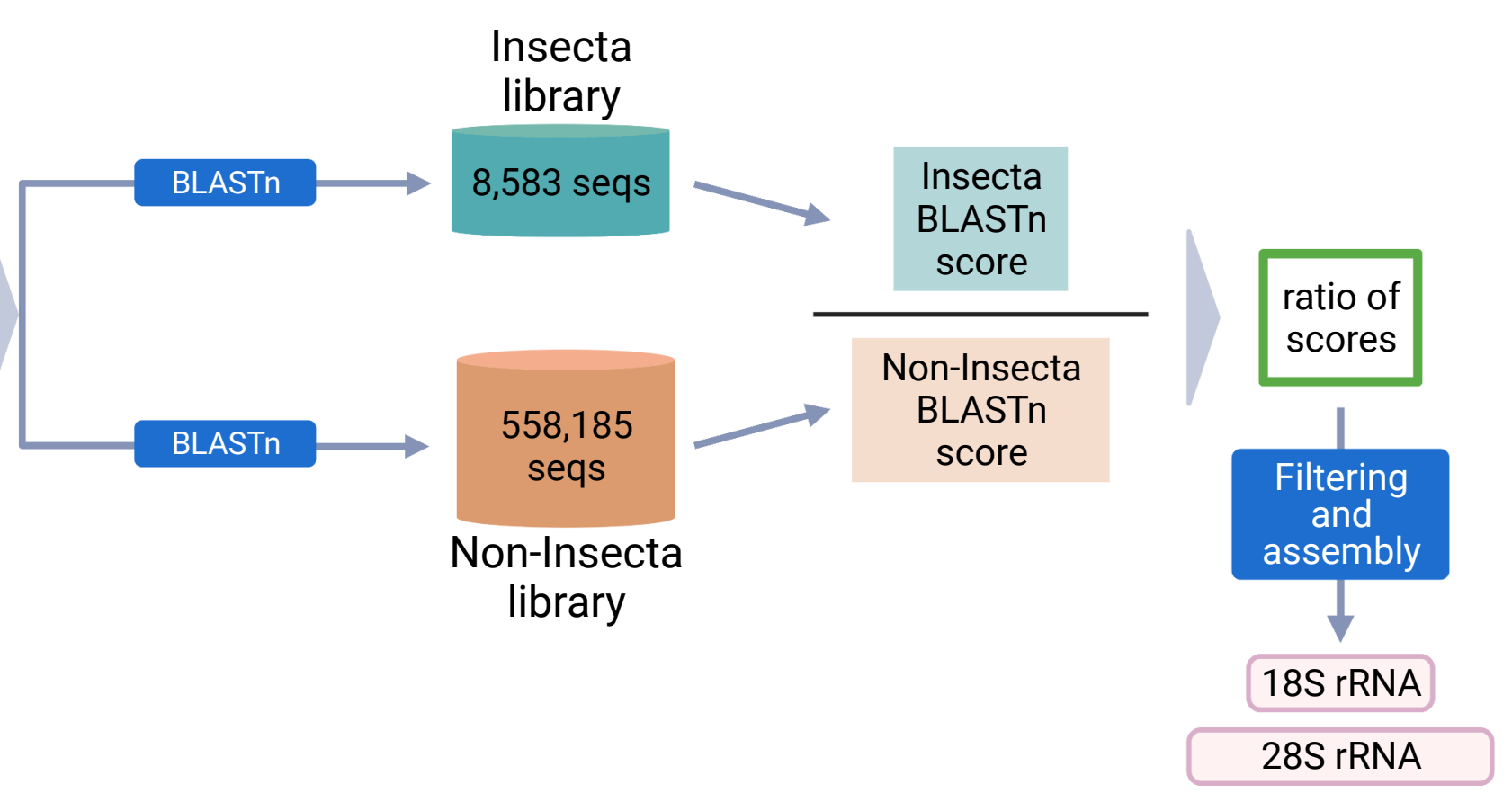

